NBER WORKING PAPER SERIES

THE QUALITY OF MEDICAL CARE, BEHAVIORAL RISK FACTORS, AND LONGEVITY GROWTH

\author{
Frank R. Lichtenberg \\ Working Paper 15068 \\ http://www.nber.org/papers/w15068
}

NATIONAL BUREAU OF ECONOMIC RESEARCH

1050 Massachusetts Avenue

Cambridge, MA 02138

June 2009

This research was supported by the Centre for Strategic Economic Studies, Victoria University (Melbourne, Australia), the Manhattan Institute for Policy Research, and Siemens AG. The views expressed herein are those of the author(s) and do not necessarily reflect the views of the National Bureau of Economic Research.

NBER working papers are circulated for discussion and comment purposes. They have not been peerreviewed or been subject to the review by the NBER Board of Directors that accompanies official NBER publications.

(C) 2009 by Frank R. Lichtenberg. All rights reserved. Short sections of text, not to exceed two paragraphs, may be quoted without explicit permission provided that full credit, including $\bigcirc$ notice, is given to the source. 
The Quality of Medical Care, Behavioral Risk Factors, and Longevity Growth

Frank R. Lichtenberg

NBER Working Paper No. 15068

June 2009

JEL No. I1,J1,O3

\begin{abstract}
$\underline{\text { ABSTRACT }}$
The rate of increase of longevity has varied considerably across U.S. states since 1991. This paper examines the effect of the quality of medical care, behavioral risk factors (obesity, smoking, and AIDS incidence), and other variables (education, income, and health insurance coverage) on life expectancy and medical expenditure using longitudinal state-level data. We examine the effects of three different measures of the quality of medical care. The first is the average quality of diagnostic imaging procedures, defined as the fraction of procedures that are advanced procedures. The second is the average quality of practicing physicians, defined as the fraction of physicians that were trained at top-ranked medical schools. The third is the mean vintage (FDA approval year) of outpatient and inpatient prescription drugs. Life expectancy increased more rapidly in states where (1) the fraction of Medicare diagnostic imaging procedures that were advanced procedures increased more rapidly; (2) the vintage of selfand provider-administered drugs increased more rapidly; and (3) the quality of medical schools previously attended by physicians increased more rapidly. States with larger increases in the quality of diagnostic procedures, drugs, and physicians did not have larger increases in per capita medical expenditure.
\end{abstract}

Frank R. Lichtenberg

Graduate School of Business

Columbia University

3022 Broadway, 614 Uris Hall

New York, NY 10027

and NBER

frank.lichtenberg@columbia.edu 
During the twentieth century, U.S. life expectancy at birth increased by almost 30 years (63\%), from 47.3 years in 1900 to 77.0 years in 2000. Nordhaus (2002) estimated that, "to a first approximation, the economic value of increases in longevity over the twentieth century is about as large as the value of measured growth in non-health goods and services" (p. 17). Murphy and Topel (2005) observed that "the historical gains from increased longevity have been enormous. Over the 20th century, cumulative gains in life expectancy were worth over $\$ 1.2$ million per person for both men and women. Between 1970 and 2000 increased longevity added about $\$ 3.2$ trillion per year to national wealth, an uncounted value equal to about half of average annual GDP over the period."

The rate of increase in longevity has varied considerably across states. Figure 1 shows the increase in life expectancy at birth during the period 1991-2004, ${ }^{1}$ by state. In the eight states with the smallest increase, life expectancy increased by only 0.31-1.16 years. In the eight states with the largest increase, life expectancy increased by 2.5-4.3 years. This paper seeks to help answer the question, why has longevity increased faster in some states than other states?

Longevity is likely to depend on a number of factors, including the quality of medical care, exogenous changes in disease incidence (e.g. the appearance of new diseases such as HIV/AIDS), income, education, and behavioral risk factors (e.g., obesity and smoking). By analyzing longitudinal state-level data, we can measure and control for many of these factors. We can also control for the effects of unobserved factors that vary across states but are relatively stable over time (e.g. climate and environmental quality), and unobserved factors that change over time but are invariant across states (e.g. changes in Federal government policies). In addition to interstate variation in longevity growth, we will analyze the growth of per capita medical expenditure.

The overall conceptual framework of the paper is depicted in Figure 2.

\footnotetext{
${ }^{1}$ Due to limitations on available data, this paper will analyze changes in longevity during the period 19912004.
} 
Figure 2

Conceptual framework

- Indicators of the quality of medical care

o Use of advanced diagnostic imaging technology

o Quality of physicians

o Vintage of outpatient and inpatient prescription drugs

- Behavioral risk factors

0 AIDS incidence

o BMI

o Smoking

- Health insurance coverage

- Per capita income

- Educational attainment

- State fixed effects

- Year fixed effects

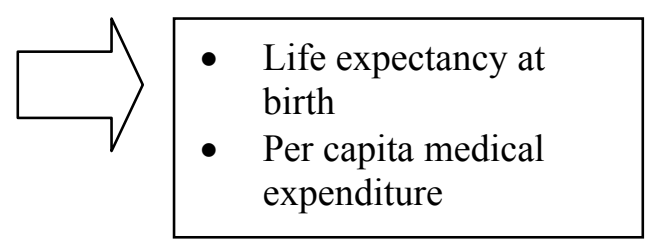

Previous literature suggests that technological innovation in general, and new goods in particular, play a key role in economic growth. In Section I, we describe our indicators of the quality of medical care. Section II describes the econometric models we will estimate. Section III describes the data sources and presents some descriptive statistics. Empirical results are presented in Section IV. Some additional evidence (based on Australian data) about the impact of advanced imaging technology on mortality is presented in Section V. The final section presents a summary and conclusions.

\section{Indicators of the quality of medical care}

We will examine the effects of three different measures of the quality of medical care. The first is the average quality of diagnostic imaging procedures, defined as the fraction of procedures that are advanced procedures. The second is the average quality of practicing physicians, defined as the fraction of physicians that were trained at top-ranked medical schools. The third is the mean vintage (FDA approval year) of outpatient and impatient prescription drugs.

Some of the indicators of the quality of medical care we examine measure the relative utilization of new vs. old medical goods and services, or the degree of influence of medical research. Economists believe that new goods and services, which are 
generated by public and private investment in research and development, are the main reason why people are better off today than they were several generations ago. Grossman and Helpman (1993) argued that "innovative goods are better than older products simply because they provide more 'product services' in relation to their cost of production." Bresnahan and Gordon (1996) stated simply that "new goods are at the heart of economic progress." Jones (1998) argues that "technological progress [is] the ultimate driving force behind sustained economic growth" (p.2), and that "technological progress is driven by research and development (R\&D) in the advanced world” (p. 89). Bils (2004) makes the case that "much of economic growth occurs through growth in quality as new models of consumer goods replace older, sometimes inferior, models."

One way to measure utilization of medical innovations is to measure the mean vintage of medical goods and services used. The vintage of a good is the year in which the good was first used. For example, the vintage of the drug atorvastatin (Lipitor) is 1997 - the year the drug was approved by the FDA. We seek to test the hypothesis that, ceteris paribus, people using newer, or later vintage, medical goods and services will be in better health, and will therefore live longer. This hypothesis is predicated on the idea that these goods and services, like other R\&D intensive products, are characterized by embodied technological progress. ${ }^{2}$

A number of econometric studies (Bahk and Gort (1993), Hulten (1992), Sakellaris and Wilson $(2001,2004))$ have investigated the hypothesis that capital equipment employed by U.S. manufacturing firms embodies technological change, i.e. that each successive vintage of investment is more productive than the last. Equipment is expected to embody significant technical progress due to the relatively high R\&Dintensity of equipment manufacturers. The method that has been used to test the equipment-embodied technical change hypothesis is to estimate manufacturing production functions, including (mean) vintage of equipment as well as quantities of

\footnotetext{
${ }^{2}$ Solow (1960, p 91): argued that "many if not most innovations need to be embodied in new kinds of durable equipment before they can be made effective. Improvements in technology affect output only to the extent that they are carried into practice either by net capital formation or by the replacement of oldfashioned equipment by the latest models..." We hypothesize that innovations may be embodied in nondurable goods (e.g. drugs) and services as well as in durable equipment.
} 
capital and labor. These studies have concluded that technical progress embodied in equipment is a major source of manufacturing productivity growth.

Although most previous empirical studies of embodied technical progress have focused on equipment used in manufacturing, embodied technical progress may also be an important source of economic growth in health care. According to the National Science Foundation, in 1997, "medical substances and devices firms had by far the highest combined R\&D intensity at 11.8 percent,... well above the 4.2-percent average for all 500 top 1997 R\&D spenders combined. The information and electronics sector ranked second in intensity at 7.0 percent." 3

\section{A. Quality of diagnostic imaging procedures} follows:

Our measure of the quality of diagnostic imaging procedures is defined as

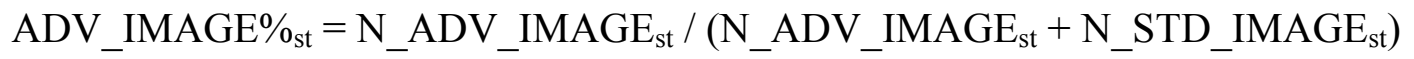

where

$$
\begin{array}{ll}
\text { ADV_IMAGE } \%_{\text {st }} & \begin{array}{l}
=\text { the fraction of standard or advanced Medicare imaging } \\
\text { procedures performed in state } \mathrm{s} \text { in year } \mathrm{t} \text { that were advanced } \\
\text { procedures }
\end{array} \\
\text { N_ADV_IMAGE }_{\mathrm{st}} & \begin{array}{l}
\text { = the number of advanced Medicare imaging procedures performed } \\
\text { in state } \mathrm{s} \text { in year } \mathrm{t} \\
=
\end{array} \\
\text { N_STD_IMAGE }_{\mathrm{st}} & \begin{array}{l}
\text { the number of standard Medicare imaging procedures performed } \\
\text { in state } \mathrm{s} \text { in year } \mathrm{t}
\end{array}
\end{array}
$$

Data on the number of procedures (submitted services), by Healthcare Common Procedure Coding System (HCPCS) code, ${ }^{4}$ carrier, ${ }^{5}$ and year, where obtained from the 1991-2004 Physician/Supplier Procedure Summary Master Files. ${ }^{6}$ These files are 100\%

\footnotetext{
${ }^{3}$ National Science Foundation, U.S. Corporate R\&D: Volume 1: Top 500 Firms in R\&D by Industry Category, http://www.nsf.gov/statistics/nsf00301/expendit.htm. The pattern of 1997 R\&D spending per employee is similar to that for R\&D intensity, with medical substances and devices again the highest at $\$ 29,095$ per employee. Information and electronics is second at \$16,381. Combined, the top 5001997 R\&D firms spent $\$ 10,457$ per employee.

${ }_{5}^{4}$ http://en.wikipedia.org/wiki/Healthcare_Common_Procedure_Coding_System

${ }_{6}^{5}$ In most cases, there is a one-to-one correspondence between a Medicare carrier and a state.

http://www.cms.hhs.gov/NonIdentifiableDataFiles/06_PhysicianSupplierProcedureSummaryMasterFile.asp
} 
summaries of all Part B Carrier and DMERC Claims processed through the Common Working File and stored in the National Claims History Repository.

We used Berenson-Eggers Type of Service (BETOS) codes developed by CMS to distinguish between standard and advanced imaging procedures. The BETOS coding system was developed primarily for analyzing the growth in Medicare expenditures. The coding system covers all HCPCS codes; assigns a HCPCS code to only one BETOS code; consists of readily understood clinical categories (as opposed to statistical or financial categories); consists of categories that permit objective assignment; is stable over time; and is relatively immune to minor changes in technology or practice patterns. ${ }^{7}$ Advanced imaging procedures (with a BETOS code beginning with I2) involve either a computed tomography (CT) $\operatorname{scan}^{8}$ or magnetic resonance imaging (MRI). ${ }^{9}$ Standard imaging procedures have BETOS codes beginning with I1.

According to the 2006 BETOS Public Use File, 544 HCPCS codes correspond to standard imaging procedures, and $152 \mathrm{HCPCS}$ codes correspond to advanced imaging procedures. For example, code 71010 (Radiologic examination, chest; single view, frontal) is a standard imaging procedure, and code 70450 (Computed tomography, head or brain; without contrast material) is an advanced imaging procedure.

As shown in Figure 3, nationwide the fraction of imaging procedures that were advanced increased from $9.3 \%$ in 1991 to $18.8 \%$ in 2004. As shown in Figure 4, the fraction of imaging procedures that were advanced in 2004 was $16-17 \%$ in the lowest six states, and $20-24 \%$ in the highest six states.

\section{B. Physician quality}

Our measure of the quality of practicing physicians is the fraction of physicians practicing in a state that graduated from a top-ranked medical school. Data on the number of practicing physicians, by state, medical school attended, and year, were

\footnotetext{
${ }^{7}$ http://www.cms.hhs.gov/HCPCSReleaseCodeSets/20 BETOS.asp\#TopOfPage

${ }^{8}$ A computed tomography scan is a study that uses a series of X-Rays to create image "slices" of the body. ${ }^{9}$ MRI is a medical imaging technique most commonly used in radiology to visualize the structure and function of the body. It provides detailed images of the body in any plane. MRI provides much greater contrast between the different soft tissues of the body than CT does, making it especially useful in neurological (brain), musculoskeletal, cardiovascular, and oncological (cancer) imaging.
} 
obtained from the American Medical Association. Medical school rankings in terms of research and primary care were obtained from the US News and World Report survey of U.S. medical schools conducted in Fall 2007. The medical school research ranking is based on a weighted average of eight indicators, and the primary-care ranking is based on seven indicators. Both rankings are based on a weighted average of indicators; four of the data indicators are used in both the research and primary-care ranking model. The research ranking factors in research activity; the primary-care ranking adds a measure of the proportion of graduates entering primary-care specialties. The methodology underlying the rankings is described in Appendix A. As shown in Table 1, research rank and primary care rank are not highly correlated.

We constructed two measures of physician quality:

MD_RESEARCH_QUAL $L_{\mathrm{st}}=\sum_{\mathrm{m}}\left(\mathrm{TOP} \mathrm{RESEARCH}_{\mathrm{m}} \mathrm{N}_{-} \mathrm{MD}_{\mathrm{mst}}\right) / \sum_{\mathrm{m}} \mathrm{N}_{-} \mathrm{MD}_{\mathrm{mst}}$ MD_PRIMCARE_QUAL ${ }_{\mathrm{st}}=\sum_{\mathrm{m}}\left(\mathrm{TOP}\right.$ _PRIMCARE $\left.\mathrm{m}_{\mathrm{m}} \mathrm{N}_{\mathrm{mst}}\right) / \sum_{\mathrm{m}} \mathrm{N}_{-} \mathrm{MD}_{\mathrm{mst}}$ where

MD_RESEARCH_QUAL ${ }_{s t}=$ the fraction of physicians practicing in state $\mathrm{s}$ in year $\mathrm{t}$ who were graduates from the top 60 medical schools ranked in terms of research

MD_PRIMCARE_QUAL st $_{\text {_ }}=$ the fraction of physicians practicing in state $\mathrm{s}$ in year $\mathrm{t}$ who were graduates from the top 60 medical schools ranked in terms of primary care

TOP_RESEARCH $\mathrm{m}_{\mathrm{m}}=1$ if medical school $\mathrm{m}$ was one of the top 60 medical schools ranked in terms of research

$=0$ otherwise

TOP_PRIMCARE $\mathrm{m}=1$ if medical school $\mathrm{m}$ was one of the top 60 medical schools ranked in terms of primary care $=0$ otherwise

N_MD ${ }_{\text {mst }}=$ the number of physicians who were graduates from medical school $\mathrm{m}$ and who are practicing in state $\mathrm{s}$ in year $\mathrm{t}$

As shown in Table 2, the mean values of both measures of physician quality declined slightly during the period 1991-2004. The fraction of practicing physicians who graduated from the top 60 medical schools ranked in terms of research declined from $45.2 \%$ to $41.0 \%$, and the fraction of physicians who graduated from the top 60 medical schools ranked in terms of primary care declined from $40.0 \%$ to $37.5 \%$. As shown in Figures 5 and 6, in 2004 both measures of physician quality exhibited significant interstate variation. 


\section{Quality of outpatient and inpatient prescription drugs}

The general definition of vintage we will use is:

where

$$
\text { vint }_{\mathrm{it}}=\underline{\Sigma_{\mathrm{p}}} \frac{\text { freq }_{\mathrm{pit}} \text { vint }_{\mathrm{p}}}{\sum_{\mathrm{a}} \text { freq }_{\mathrm{pit}}}
$$

vint $_{\text {it }}=$ the mean vintage of products and services used in state $\mathrm{i}$ in year $\mathrm{t}$

freq $_{\text {pit }}=$ the frequency of use of product or service $\mathrm{p}$ in state $\mathrm{i}$ in year $\mathrm{t}$

$\operatorname{vint}_{\mathrm{p}}=$ the vintage (year of first use) of product or service $\mathrm{p}$

We will measure the mean vintage of outpatient prescription drugs paid for by the state's Medicaid program, and the mean vintage of drugs administered by providers (e.g., chemotherapy) to Medicare beneficiaries. The number of prescriptions paid for by Medicaid is very large: according to the Medical Expenditure Panel Survey, in 1997, Medicaid paid for about 201 million prescriptions-11\% of all U.S. prescriptions. Moreover, we show in Appendix B that the extent of utilization of new drugs in the Medicaid program is strongly correlated with the extent of utilization of new drugs in general: the vintage of non-Medicaid (and all) rx's tended to increase more in states with larger increases in the vintage of Medicaid rx's.

Drugs administered by providers are quite different from self-administered drugs, and Medicare pays for a substantial fraction of the former. In 2004, Medicare paid providers $\$ 7.6$ billion for performing 522 million pharmaceutical procedures. ${ }^{10}$

\section{Adjusting for state-specific changes in the distribution of disease}

If there have been state-specific changes in the distribution of disease, and drug vintage is correlated with disease severity (e.g., newer drugs tend to be for less severe diseases), the coefficient on drug vintage could be biased. However, we can eliminate any potential bias by constructing an alternative (fixed-weighted) index of drug vintage.

Consider the following simplified model of life expectancy:

$$
\mathrm{LE}=\beta_{1} \mathrm{~V}+\beta_{2} \mathrm{~S}
$$

\footnotetext{
${ }^{10}$ Source: CMS, Medicare Part B Physician/Supplier Data by BETOS, Calendar Year 2004, http://www.cms.hhs.gov/MedicareFeeforSvcPartsAB/Downloads/BETOS04.pdf.
} 
where $\mathrm{LE}=$ life expectancy, $\mathrm{V}=$ drug vintage, and $\mathrm{S}=$ (mean) disease severity. Hence

$$
\Delta \mathrm{LE}=\beta_{1} \Delta \mathrm{V}+\beta_{2} \Delta \mathrm{S}
$$

Suppose that $\beta_{1}>0$ and that $\beta_{2}<0$. For simplicity, suppose that there are just 2 diseases: a high-severity disease and a low-severity disease. Mean disease severity depends on the proportions of patients with each disease:

$$
\mathrm{S}=\operatorname{high} \% \mathrm{~S}_{\mathrm{H}}+(1-\operatorname{high} \%) \mathrm{S}_{\mathrm{L}}=\mathrm{S}_{\mathrm{L}}+\left(\mathrm{S}_{\mathrm{H}}-\mathrm{S}_{\mathrm{L}}\right) \text { high } \%
$$

where high $\%$ = the percent of patients with the high-severity disease, $\mathrm{S}_{\mathrm{H}}=$ severity of the high-severity disease, $\mathrm{S}_{\mathrm{L}}=$ severity of the low-severity disease, and $\mathrm{S}_{\mathrm{H}}>\mathrm{S}_{\mathrm{L}}$. Assuming that $\mathrm{S}_{\mathrm{H}}$ and $\mathrm{S}_{\mathrm{L}}$ are constant, $\Delta \mathrm{S}=\left(\mathrm{S}_{\mathrm{H}}-\mathrm{S}_{\mathrm{L}}\right) \Delta$ high\%, and

$$
\Delta \mathrm{LE}=\beta_{1} \Delta \mathrm{V}+\beta_{2}\left(\mathrm{~S}_{\mathrm{H}}-\mathrm{S}_{\mathrm{L}}\right) \Delta \mathrm{high} \%
$$

The change in life expectancy is directly related to the change in drug vintage and inversely related to the change in the percent of patients with the high-severity disease.

Suppose that drugs for the low-severity disease (nervous system disorders) tend to be newer than drugs for the high-severity disease (cardiovascular disease), so that there is an inverse correlation across states between $\Delta \mathrm{V}$ and $\Delta \mathrm{high} \%$ : states with smaller increases in mean severity will have larger increases in drug vintage. In this case, failure to control for changes in severity ( $\Delta$ high\%) will result in overestimation of the effect of drug vintage on life expectancy.

We will control for the incidence of one highly severe disease-AIDS - but unfortunately data on the incidence of other diseases, by state and year, are not available. Therefore direct measurement of mean disease severity (or the percent of patients with high-severity diseases) by state and year is not feasible. However, provided that the distribution of drugs utilized, by therapeutic class, is closely related to the distribution of patients, by disease, we can eliminate any potential bias in the vintage coefficient by using the following fixed-weighted index of drug vintage:

$$
\mathrm{V}^{\prime}{ }_{\text {it }}=\Sigma_{\mathrm{c}} \text { class } \%_{\text {ci. }} \mathrm{V}_{\text {cit }}
$$

where $\mathrm{V}_{\text {cit }}=$ the mean vintage of prescriptions in therapeutic class $\mathrm{c}$ in state $\mathrm{i}$ in year $\mathrm{t}$, and class $\%_{\text {ci. }}=$ the mean fraction of prescriptions in therapeutic class $\mathrm{c}$ in state i during the entire sample period, i.e. class $\%_{\text {ci. }}=(1 / \mathrm{T}) \Sigma_{\mathrm{t}}$ class $\%_{\text {cit }}$, where class $\%_{\text {cit }}=$ the fraction of prescriptions in therapeutic class $\mathrm{c}$ in state $\mathrm{i}$ in year $\mathrm{t}$. 
Changes over time in the fixed-weighted index V', are entirely due to withintherapeutic class changes in drug vintage, not at all to between-class changes, i.e. shifts in the distribution of drugs by therapeutic class. In contrast, changes in the standard vintage index $\left(\mathrm{V}_{\mathrm{it}}=\Sigma_{\mathrm{c}}\right.$ class $\left.\%{ }_{\text {cit }} \mathrm{V}_{\text {cit }}\right)$ are due to between- as well as within-class changes in vintage.

We will construct fixed-weighted indices of drug vintage using data from the Veterans Administration's National Drug File (U.S. Dept. of Veterans Affairs (2007)) on the therapeutic class of each product. The VA drug classification is hierarchical, and has over 500 classes and subclasses. We will classify drugs at the highest level of the VA classification system, which has 32 classes. Table 3 shows data on the distribution and vintage of Medicaid prescriptions in 1991 and 2004, by major VA therapeutic class. In 2004, two classes of drugs (central nervous system medications and cardiovascular medications) accounted for half of Medicaid prescriptions. The share of Medicaid prescriptions that were central nervous system medications increased from 19\% in 1991 to $29 \%$ in 2004 . The mean vintage of central nervous system medications increased much more than the mean vintage of cardiovascular medications (16.5 years vs. 6.5 years). However for the nation as a whole, the fixed-weighted vintage index increased more during 1991-2004 than the standard index (11.4 years vs. 9.4 years).

We will estimate models using both the standard index and the fixed-weighted index of drug vintage. Performing this sensitivity analysis is useful, but eliminating the effects of shifts in the distribution of drugs by therapeutic class on vintage is not necessarily appropriate. If the rate of innovation varies across diseases/drug classes, states may benefit from innovation by changing the distribution of drugs consumed, by class, as well as by using newer drugs within drug classes.

\section{E. Potential reasons for variation in the rate of increase of drug vintage}

The rate of increase in drug vintage may vary across states due to both interstate differences in the types of diseases afflicting the population, and differences in the drugs used to treat given diseases. Suppose that

$$
\Delta \mathrm{V}_{\mathrm{i}}=\Sigma_{\mathrm{d}} \text { share }_{\mathrm{di}} \Delta \mathrm{V}_{\mathrm{d}}
$$


where

$\Delta \mathrm{V}_{\mathrm{i}}=$ the increase in the mean vintage of drugs in state $\mathrm{i}$

share $_{\mathrm{di}}=$ the fraction of state i's residents who have disease $\mathrm{d}$

$\Delta \mathrm{V}_{\mathrm{d}}=$ the increase in the mean vintage of drugs to treat disease $\mathrm{d}$

Even if the increase in the mean vintage of drugs to treat each disease is the same in every state, differences in the fractions of state residents who have various diseases $\left(\right.$ share $\left._{\mathrm{di}}\right)$ will result in interstate variation in the increase in the mean vintage of drugs. ${ }^{11}$

The relative incidence of various diseases does vary across states. This is illustrated by Figure 7, which plots the state-level incidence rate (cases per 100,000) of colon \& rectum cancer against the incidence rate of prostate cancer for males in 2002. The correlation across states between these two incidence rates is not significantly different from zero $(\mathrm{p}$-value $=0.61)$.

Moreover, due to medical practice variation, the increase in the mean vintage of drugs to treat any given disease is likely to vary across states. Medical practice variation is a well-documented phenomenon: there are 2514 citations for this term in the PubMed database. The Dartmouth Atlas of Health Care Project (Wennberg (2006)) has demonstrated "glaring variations in how health care is delivered across the United States."

Skinner and Staiger (2005) argue that medical practice variation may be partly due to variation in the frequency and likelihood of informational exchanges through networks or other social activities, which may in turn be related to both average educational attainment and other measures of social capital. They compared the adoption of several important innovations during the 20th century, ranging from advances at midcentury in hybrid corn and tractors, to medical innovations in the treatment of heart attacks at the end of the century. They found a very strong state-level correlation with regard to the adoption of new and effective technology, and this correlation held across a variety of industries and time periods. These results are suggestive of state-level factors associated with barriers to adoption. These barriers may be related to information or network flows, given that farmers, physicians, and individual computer users conduct

\footnotetext{
${ }^{11}$ Our econometric model will control (via state fixed effects) for the effects of permanent, or relatively stable, differences between states in the relative incidence of various diseases.
} 
their business in often small and isolated groups, and therefore are most vulnerable to potential information asymmetries.

Interstate differences in government health care policy also contribute to practice variation. In the last few years, some state Medicaid programs and private managed care plans have restricted access to certain drugs, especially newer, more expensive drugs. One important type of restriction is a "prior authorization" requirement: a prescription will not be dispensed without prior authorization by program officials. Lichtenberg (2005d) examined the effect of access restrictions on the vintage of drugs used by Medicaid enrollees. The sample included 50 brand name drugs in six important therapeutic classes: antidepressants, antihypertensives, cholesterol-lowering drugs, diabetic drugs, osteoporosis/menopause drugs, and pain management medications. The extent of access restrictions varied considerably across states. Twelve states did not restrict any of the 50 drugs. Five states restricted over $47 \%$ of the drugs, and oneVermont - restricted 43 of the 50 drugs. The vintage of Medicaid prescriptions increased more slowly in states that imposed more access restrictions. ${ }^{12}$

\section{Econometric model}

We will investigate the effects of indicators of the quality of medical care, behavioral risk factors, and other variables on life expectancy and medical expenditure by estimating models of the following form:

$$
\mathrm{Y}_{\mathrm{st}}=\beta \mathrm{X}_{\mathrm{st}}+\alpha_{\mathrm{s}}+\delta_{\mathrm{t}}+\varepsilon_{\mathrm{st}} \quad\left(\mathrm{s}=1, \ldots, 50 ;^{13} \mathrm{t}=1991, \ldots, 2004\right)
$$

where $\mathrm{Y}$ is one of the following variables:

$\mathrm{LE}_{\text {st }}=$ life expectancy at birth in state $\mathrm{s}$ in year $\mathrm{t}$ expend $_{\mathrm{st}}=$ the $\log$ of per capita medical expenditure in state $\mathrm{s}$ in year $\mathrm{t}$

and $\mathrm{X}$ includes a subset of the following variables:

\footnotetext{
${ }^{12}$ Lichtenberg (2006) presents a theoretical argument that the vintage of drugs is also likely to depend on the extent of prescription drug coverage, and empirical evidence that supports this argument.

${ }^{13}$ Arizona is excluded from the sample because it does not participate in the Medicaid Drug Rebate Program.
} 


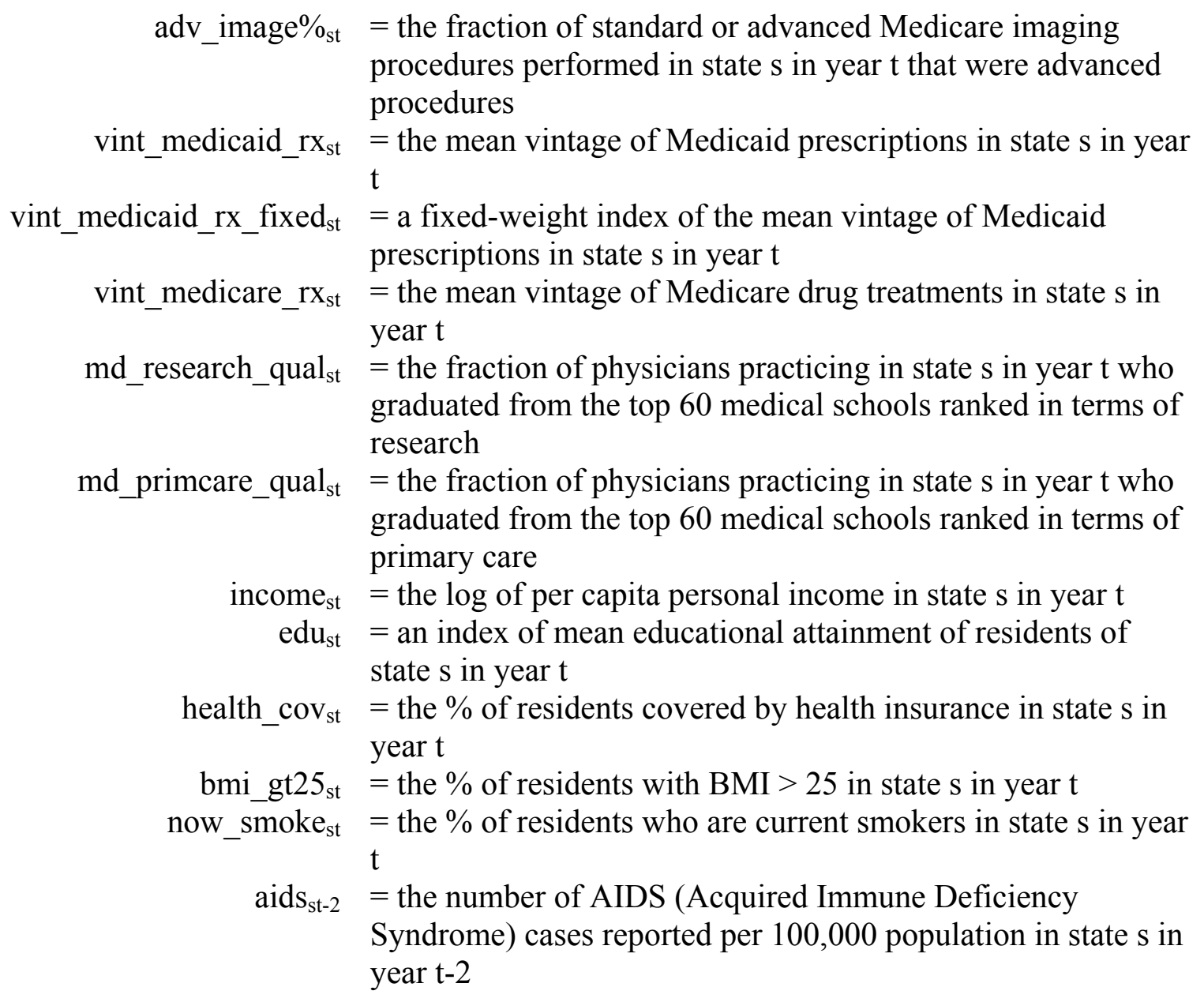

$\alpha_{s}$ and $\delta_{t}$ represent state fixed effects and year fixed effects, respectively. Eq. (1) will be estimated by weighted least squares (WLS), weighting by pop it, state i's population in year $\mathrm{t}$.

In principle, there is some risk of feedback, or reverse causality, from life expectancy to some of the explanatory variables, especially mean income and education. Ceteris paribus, increases in life expectancy lead to an increase in the fraction of the population that is elderly. As shown in Figure 8, mean income and education of elderly people is significantly lower than that of non-elderly people. Hence unobserved shocks that increase a state's longevity could reduce its mean income and education, causing a downward bias in the coefficients of these variables. However, the share of the population that is elderly need not be increasing faster in states with larger increase in life expectancy; these states could have higher birth and/or net immigration rates. 
In practice, the share of the population that is elderly is increasing faster in states with larger increase in life expectancy, but the relationship is not very strong. By using estimates of this relationship and the age profiles shown in Figure 8, we obtained estimates of the feedback effect of life expectancy on income and education, via population age structure. These calculations indicated that the downward biases in the income and education coefficients in the longevity equations would be extremely small.

\section{Data sources and descriptive statistics}

Life expectancy. The government does not publish data on life expectancy, by state, so we constructed estimates using data on the number of deaths by age group, year, and state of residence from the Multiple Cause-of-Death Mortality Data from the National Vital Statistics System of the National Center for Health Statistics. ${ }^{14}$ Each record in the microdata is based on information abstracted from death certificates filed in vital statistics offices of each State and District of Columbia. The average number of records (deaths) per year is about 2.3 million. We also used population data from CDC Wonder Bridged-Race Population Estimates (Vintage 2004, http://wonder.cdc.gov/Bridged-Racev2004.HTML). ${ }^{15}$ As shown in Figure 9, the population-weighted means of my state estimates of LE are quite similar to the NCHS national estimates.

Per capita income. These data were obtained from the Bureau of Economic Analysis State Annual Personal Income database (http://www.bea.gov/regional/spi/). Per capita medical expenditure. The CMS Health Accounts by State database provides data on the following categories of personal health care expenditure, by state and year (1980-2004).

Vintage of Medicaid prescriptions. The mean vintage of Medicaid prescriptions is defined as follows:

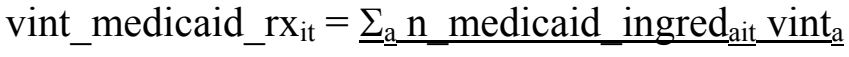

$$
\begin{aligned}
& \Sigma_{\mathrm{a}} \mathrm{n} \text { _medicaid_ingred }{ }_{\text {ait }}
\end{aligned}
$$

\footnotetext{
${ }^{14}$ Murray et al (2006) also computed state and local estimates of life expectancy.

${ }^{15}$ We computed life expectancy using the following age classification: under 1 year, 1-4 years, 5-9 years, 10-14 years, 15-19 years, 20-24 years, 25-29 years, 30-34 years, 35-39 years, 40-44 years, 45-49 years, 5054 years, 55-59 years, 60-64 years, 65-69 years, 70-74 years, 75-79 years, 80-84 years, 85 years and over.
} 
where

$\mathrm{n} \_$medicaid_ingred $\mathrm{d}_{\text {ait }}=$ the number of Medicaid prescriptions containing active ingredient $\mathrm{a}$ in state $\mathrm{i}$ in year $\mathrm{t}$

$\operatorname{vint}_{\mathrm{a}}=$ the vintage (year of initial FDA approval) of active ingredient a.

The first of these variables is constructed as follows:

$\mathrm{n} \_$medicaid_ingred $\mathrm{ait}_{\mathrm{p}}=\Sigma_{\mathrm{p}} \mathrm{n} \_$medicaid_prod $\mathrm{p}_{\mathrm{pit}} \mathrm{d}_{\mathrm{pa}}$

where

$\mathrm{n} \_$medicaid_prod $\mathrm{p}_{\mathrm{pit}}=$ the number of Medicaid prescriptions for product $\mathrm{p}$ in state $\mathrm{i}$ in year $\mathrm{t}$

$\mathrm{d}_{\mathrm{pa}}=1$ if product $\mathrm{p}$ contains active ingredient a

$=0$ if product $\mathrm{p}$ does not contain active ingredient a

$\Sigma_{\mathrm{a}} \mathrm{d}_{\mathrm{pa}}=1$ if product $\mathrm{p}$ is a single-ingredient product; $\Sigma_{\mathrm{a}} \mathrm{d}_{\mathrm{pa}}>1$ if it is a combination

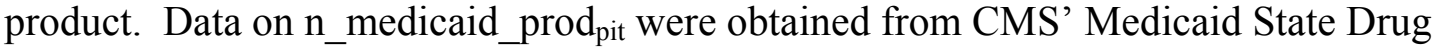
Utilization files (http://www.cms.hhs.gov/MedicaidDrugRebateProgram/SDUD/list.asp), which cover outpatient drugs paid for by State Medicaid agencies since the inception of the Medicaid Drug Rebate Program. Forty nine states (Arizona is excluded) and the District of Columbia cover drugs under the Medicaid Drug Rebate Program. The Medicaid data disclose the number of prescriptions, by product (NDC code), state, and year. There are currently over 37,000 products in the Medicaid Drug Product Data file (http://www.cms.hhs.gov/MedicaidDrugRebateProgram/09 DrugProdData.asp).

Data on $\mathrm{d}_{\mathrm{pa}}$ were obtained from the ndc_denorm table in the Multum Lexicon database (http://www.multum.com/Lexicon.htm). There are currently over 2100 active ingredients in this database. Table 4 shows the top 25 active ingredients contained in 2004 Medicaid prescriptions, ranked by number of prescriptions.

Data on vint $\mathrm{a}_{\mathrm{a}}$ were obtained from the Drugs@FDA database, produced by the FDA Center for Drug Evaluation and Research (http://www.fda.gov/cder/drugsatfda/datafiles/default.htm). This database includes several tables. The product table enumerates properties of the products included in each application, including their active ingredient(s). The supplements table provides the approval history for each application, including dates of approval. We define vint $\mathrm{a}_{\mathrm{a}}$ as the earliest approval date of any product that contains active ingredient a. 
Vintage of Medicare drug treatments. Medicare is a health insurance program for people age 65 or older, people under age 65 with certain disabilities, and people of all ages with End-Stage Renal Disease (permanent kidney failure requiring dialysis or a kidney transplant). All Medicare enrollees are covered by Medicare Part A (Hospital Insurance). Most Medicare enrollees elect to pay a monthly premium for Part B. Medicare Part B helps cover doctors' services and outpatient care. It also covers some other medical services that Part A doesn't cover, such as some of the services of physical and occupational therapists, and some home health care. Part B helps pay for these covered services and supplies when they are medically necessary. In 2004, about 39 million Americans were enrolled in Medicare Part B.

Prior to January 1, 2006, when Medicare Part D was established, Medicare did not pay for most outpatient drugs, but the Medicare Part B (Medical Insurance) program did pay for drugs administered by health care providers, e.g. chemotherapy.

The Medicare drug vintage measure is similar to the Medicaid drug vintage measure, with one exception. For reasons discussed below, the Medicare index is expenditure-weighted, rather than quantity weighted:

where

$$
\text { vint_medicare_rx } x_{i t}=\underline{\sum_{a}} \underset{\sum_{a} \text { expend medicare ingred }}{\sum_{\text {ait }} \text { expedicare_ingred }} \underline{a i t}_{a}
$$

expend_medicare_ingred $\mathrm{ait}_{\mathrm{a}}=$ expenditure on Medicare drug treatments containing active ingredient $\mathrm{a}$ in state $\mathrm{i}$ in year $\mathrm{t}$

This variable is defined as follows:

expend_medicare_ingred $\mathrm{d}_{\mathrm{ait}}=\Sigma_{\mathrm{d}}$ expend_medicare_drug $\mathrm{dit}_{\mathrm{da}}$

where

expend_medicare_drug dit $_{\text {_ }}=$ expenditure on Medicare drug treatment $\mathrm{d}$ in state $\mathrm{i}$ in year $\mathrm{t}$

$\mathrm{e}_{\mathrm{da}}=1$ if Medicare drug treatment $\mathrm{d}$ contains active ingredient a

$=0$ if Medicare drug treatment $\mathrm{d}$ does not contain active ingredient a

Data on expend_medicare_drug dit $_{\text {Were obtained from annual Physician/Supplier }}$ Procedure Summary (PSPS) Master Files produced by CMS for each of the years 1991- 
2004. Each file is a 100\% summary of all Part B Carrier and DMERC Claims processed through the Common Working File and stored in the National Claims History Repository. The files are large; the 2004 file has over 12 million records. The file enables us to compute total submitted services and charges, total allowed services and charges, total denied services and charges, and total payment amounts, by Medicare carrier and procedure. In most cases there is a one-to-one correspondence between a carrier and a state, so we can measure utilization and expenditure, by procedure and state.

As discussed in the technical documentation for the PSPS Master Files, Medicare carriers often make erroneous reports of service counts, but not of expenditures:

Service counts for drugs should be reported using pricing units, e.g. J0120: Injection, Tetracycline up to $250 \mathrm{mg}$. In this example, $250 \mathrm{mg}=1$ pricing unit or service. If the injection were for $500 \mathrm{mg}$ then the pricing unit or service would be equal to 2 , i.e. $500 \mathrm{mg} / 250 \mathrm{mg}=2$ pricing units or services. Many carriers are reporting the milligrams in the service count and MTUS Fields, e.g. $250 \mathrm{mg}$ instead of 1 pricing unit. As a result the number of services are inflated, thereby deflating the average allowed charge. ${ }^{16}$

These reporting errors appear to cause spurious fluctuations in aggregate Medicare drug treatment service counts, but not in expenditures. Therefore, while we believe that a quantity-weighted vintage index is preferable to an expenditure-weighted index, due to errors in reporting service counts we will use an expenditure-weighted index of Medicare drug treatments.

Data on $\mathrm{e}_{\mathrm{da}}$ were obtained from the ndc_denorm table in the Multum Lexicon database.

Table 5 shows the top 25 active ingredients contained in 2004 Medicare drug treatments, ranked by total services count. Comparison of Tables 4 and 5 indicates that the drugs administered by providers to Medicare beneficiaries are quite different from outpatient drugs used by Medicaid beneficiaries.

Demographic characteristics and behavioral risk factors. Data on body mass index (BMI), current smoking participation, health insurance coverage, and educational attainment were obtained from the Behavioral Risk Factor Surveillance System (BRFSS), which is the world's largest telephone survey. The BRFSS was established by the CDC

\footnotetext{
${ }^{16}$ Source: CMS, "2004 Limitations for the Physician/Supplier Procedure Summary Master File.”
} 
in 1984, and was designed to collect state-level data. By 1994, all states, the District of Columbia, and three territories were participating in the BRFSS.

Data on the incidence of AIDS (the number of AIDS cases reported by state and local health departments) were obtained from the CDC's AIDS Public Information Data Set (http://www.cdc.gov/hiv/software/apids.htm). This data set contains counts of AIDS, by demographics; location (region and selected metropolitan areas); case-definition; month/year and quarter-year of diagnosis, report, and death (if applicable); and HIV exposure group (risk factors for AIDS). The data set covers the period 1981-2002. As noted above, the measure of aids incidence we will include in our model of life expectancy will be the number of AIDS cases reported per 100,000 population lagged two years. Using this measure allows us to have the sample period end in 2004 rather than 2002. Also, Lichtenberg (2006) provides evidence that even before highly-active retroviral therapy was introduced in the mid-1990s, life expectancy of AIDS patients at time of diagnosis was 3.7 years, so overall life expectancy may depend on lagged AIDS incidence more than it depends on contemporaneous AIDS incidence. ${ }^{17}$

Table 6 shows population-weighted sample means of the variables included in eq. (1), by year. Figure 10 shows the increase in the fixed-weighted drug vintage index 1991-2004, by state

\section{Empirical results}

\section{A. Life expectancy}

Estimates of models of life expectancy at birth are shown in the top half of Table 7. The dependent variable in models $1-3$ is life expectancy at birth. ${ }^{18}$ The three models include different sets of indicators of the quality of medical care. Model 1 includes the basic Medicaid drug vintage measure vint_medicaid_rx (with changing therapeutic-class weights) and both measures of physician quality (md_primcare_qual and md_research_qual). Model 2 includes the fixed-weight Medicaid drug vintage measure

\footnotetext{
${ }^{17}$ By 2001, life expectancy of AIDS patients at time of diagnosis is estimated to have increased to about 26 years.

${ }^{18}$ Estimates of models of the $\log$ of life expectancy at birth are quite consistent with these estimates.
} 
vint_medicaid_rx_fixed (with fixed therapeutic-class weights) and both measures of physician quality (md_primcare_qual and md_research_qual). Model 3 includes the fixed-weight Medicaid drug vintage measure and just the primary-care measure of physician quality.

With only one exception, all of the indicators of the quality of medical care have positive and statistically significant effects on life expectancy in all three models. ${ }^{19}$ In all three models, the advanced imaging coefficient is positive and highly significant ( $\mathrm{p}$-value $\leq .003$ ). This signifies that life expectancy increased more rapidly (and that the agestandardized mortality rate declined more rapidly) in states in which the fraction of Medicare imaging procedures that were advanced procedures increased more rapidly. Below we will discuss the magnitude of the estimated effect of the increased relative utilization of advanced imaging procedures on life expectancy. But first we will review the signs and significance of the other variables included in models 1-3.

The coefficients on both the basic Medicaid drug vintage measure (in model 1) and the fixed-weight Medicaid drug vintage measure (in models 2 and 3) are positive and highly significant. The vintage of Medicare drug treatments also has a positive and highly significant effect. Since expenditure on self-administered drugs is much larger than expenditure on provider-administered drugs, it is not surprising that the coefficients on Medicare drug vintage are much smaller than the coefficients on Medicaid drug vintage.

Although the research-quality of medical schools attended by physicians is insignificant in model 1 and only marginally significant in model 2 , the primary-carequality of medical schools attended by physicians is positive and significant in all three models. Almost three fourths of the medical school primary care quality ranking is based on the following criteria: peer assessment score, assessment score by residency directors, student selectivity, faculty resources, mean MCAT score, mean undergraduate GPA, and acceptance rate. States in which the primary-care-quality of medical schools attended by physicians declined more slowly had larger increases in life expectancy.

\footnotetext{
${ }^{19}$ The exception is the research-quality of the medical schools attended by physicians. Since U.S. News and World Report uses some of the same data to assess research quality as it does to assess primary-care quality, failure to detect an independent effect of research quality is not too surprising.
} 
Now let's consider the effects of three behavioral risk factors-obesity, AIDS, and smoking - on life expectancy. As one would expect, the coefficient on the fraction of the population with a BMI greater than 25 and the coefficient on the AIDS incidence rate are negative and highly significant in models 1-3. States with below-average increases in overweight/obesity prevalence and above-average declines in AIDS incidence had above-average increases in life expectancy during the period 1991-2004. Although the coefficient on smoking has the expected negative sign in all three models, it is insignificant in models 1 and 2 and only marginally significant (p-value $=.09)$ in model 3.

Models 1-3 include three additional variables - health insurance coverage, educational attainment, and per capita income - that might be expected to affect life expectancy. At the state level, long-term changes in life expectancy seem to be uncorrelated with changes in both health insurance coverage and educational attainment. $^{20}$ The life expectancy of a state's residents appears to depend on education, but it is the quality of its physicians' medical education, not the number of years of schooling of state residents that matters. The coefficient on per capita income is negative and significant: states with high income growth had smaller longevity increases, ceteris paribus. Some previous investigators have also found evidence of a non-monotonic or even inverse relationship between income and longevity. Uchida et al (1992) found that "for [Japanese] females high income was the factor significantly decreasing life expectancy at 65 years of age in 1980.” Hupfeld (2008) theoretically derived a nonmonotonic relationship between income and longevity, based on heterogeneous elasticities of labor supply and otherwise standard assumptions. He analyzed this relationship empirically for pensioners in the public pension system in Germany, and find that "the relationship between income and life expectancy is indeed non-monotonic for major sub-groups in the data." And Ruhm (2004) argued that "although health is conventionally believed to deteriorate during macroeconomic downturns, the empirical

\footnotetext{
${ }^{20}$ The nature of the effect of health insurance coverage on life expectancy is not entirely clear on theoretical grounds. Some analysts argue that people without health insurance receive necessary medical care, but that medical care is provided to them in an inefficient manner, e.g. in emergency rooms. Also, low health insurance coverage could be partly due to decisions by young, healthy people not to enroll in health plans. In that case, increases in coverage could be inversely correlated with increases in life expectancy.
} 
evidence supporting this view is quite weak and comes from studies containing methodological shortcomings that are difficult to remedy. Recent research that better controls for many sources of omitted variables bias instead suggests that mortality decreases and physical health improves when the economy temporarily weakens. This partially reflects reductions in external sources of death, such as traffic fatalities and other accidents, but changes in lifestyles and health behaviors are also likely to play a role."

Now we will use the estimates of the parameters of models 1-3 to estimate the 1991-2004 change in life expectancy that was attributable to each of the factors included in the models. The change attributable to a factor $\mathrm{X}$ is calculated as follows: $\beta\left(\mathrm{X}_{2004}-\right.$ $\left.X_{1991}\right)$, where $\beta$ is the coefficient on that factor, and $X_{2004}$ and $X_{1991}$ are the populationweighted mean values of X in 2004 and 1991, respectively. These calculations are shown in Table 8. Between 1991 and 2004, life expectancy at birth increased 2.37 years. ${ }^{21}$ The estimates imply that the increased use of advanced imaging technology increased life expectancy by $0.62-0.71$ years during this period. The coefficient on the basic Medicaid drug vintage measure (vint_medicaid_rx) in model 1 implies that use of newer outpatient prescription drugs increased life expectancy by 1.26 years. The coefficient on the fixedweight Medicaid drug vintage measure (vint_medicaid_rx_fixed) in models 2 and 3 implies that the increase in life expectancy attributable to use of newer outpatient prescription drugs was about 20\% smaller: 0.96-1.08 years. The vint_medicare_rx coefficients imply that use of newer provider-administered drugs increased life expectancy by $0.48-0.54$ years. Overall, therefore, use of newer self- and provideradministered drugs increased life expectancy by about 1.5 years.

Although the average values of the first two indicators of the quality of medical care increased during the period 1991-2004, the average value of the quality of medical schools attended by practicing physicians declined. Model 2 implies that the decline in both primary-care and research quality reduced life expectancy by 0.47 years; Model 3, which includes only the primary-care quality measure (the research quality measure is only marginally significant in model 2) implies that the decline in primary-care quality reduced life expectancy by 0.28 years.

\footnotetext{
${ }^{21}$ Since the models include year fixed effects, the sum of the changes in life expectancy attributable to each of the factors need not be equal to the actual change in life expectancy.
} 
Another factor that apparently reduced longevity growth during the period 19912004 was the rise from $44 \%$ to $59 \%$ in the fraction of the population that was overweight or obese. The estimates imply that this trend reduced the increase in life expectancy by .58-.68 years. The increase in this risk factor was partly offset by a decline in another risk factor - the incidence of AIDS, which is estimated to have increased life expectancy by .18-.20 years. The estimates also suggest that the small decline in smoking prevalence may have increased life expectancy by about 0.10 years.

During the period 1991-2004, real per capita income (in 2006 dollars) increased from $\$ 21,102$ to $\$ 25,465$. $^{22}$ The estimates imply that this $19 \%$ increase in income reduced life expectancy by .34-.43 years. The sum of the contributions of all of the factors to the increase in life expectancy is in the 0.85-1.32 year range. Consequently, between 1.05 and 1.52 years of the 2.37-year increase in life expectancy is unexplained (i.e., captured by the year fixed effects).

\section{B. Per capita medical expenditure}

Estimates of models of (the log of) per capita personal health care expenditure are shown in the bottom half of Table 7. These models include the same regressors as the life expectancy models in the top of the table. None of the coefficients on advanced imaging, drug vintage, or physician quality are statistically significant. This indicates that, although states with larger increases in the quality of diagnostic procedures, drugs, and physicians had larger increases in life expectancy, they did not have larger increases in per capita medical expenditure. This may be the case because, while newer diagnostic procedures and drugs are more expensive than their older counterparts, they may reduce the need for costly additional medical treatment. The absence of a correlation across states between medical innovation and expenditure growth is inconsistent with the view

\footnotetext{
${ }^{22}$ Source: U.S. Census Bureau, Historical Income Tables - People, Table P-1. CPS Population and Per Capita, Money Income, All Races: 1967 to 2006, http:/www.census.gov/hhes/www/income/histinc/p01ar.html
} 
expressed by the Kaiser Family Foundation (2007), citing Rettig (1994), that "advances in medical technology have contributed to rising overall U.S. health care spending."

The prevalence of obesity and smoking do not appear to affect per capita medical expenditure, but the incidence of AIDS has a significant positive effect. This is to be expected, since Duggan and Evans (2008) estimated that in California during the period 1994-2003, average annual Medicaid medical expenditure (the sum of pharmaceutical, outpatient and inpatient expenditure) per AIDS patient was about $\$ 18,800$.

Increased health insurance coverage is associated with lower growth in per capita medical expenditure. One possible explanation is that lack of employer-based health insurance (which may result from employment in high-turnover industries) causes underinvestment in the health of workers and higher medical expenditure in retirement. Fang and Gavazza (2007) found that employers in industries with high turnover rates are much less likely to offer health insurance to their workers, and that individuals who were employed in high turnover industries have higher medical expenditure when retired.

Growth in per capita medical expenditure is also positively correlated with growth in educational attainment and (more weakly) with income growth. Many previous studies have shown that medical care is a normal good (income elasticity greater than zero); some studies (Gerdtham and Jonsson (2000)) suggest that it is a luxury good (income elasticity greater than one).

\section{Some additional evidence (based on Australian data) about the impact of advanced imaging technology on mortality}

The availability of data from Australia's universal health care system, Medicare Australia, allows us to provide some additional evidence about the impact of advanced imaging technology on mortality. Medicare Australia was introduced in 1984 to provide eligible Australian residents with affordable, accessible and high-quality health care. Medicare was established based on the understanding that all Australians should contribute to the cost of health care according to their ability to pay. It is financed through progressive income tax and an income-related Medicare levy. Medicare provides access to free treatment as a public (Medicare) patient in a public hospital, and free or 
subsidized treatment by medical practitioners including general practitioners, specialists, participating optometrists or dentists (for specified services only).

On its website, Medicare Australia publishes data on the number of services provided, by category (e.g. Category 5: Diagnostic Imaging Services), group (e.g. Group I2: Computerised Tomography), state, gender, age group (10 age groups: 0-4 years, 5-14 years, 15-24 years, etc.), and year (1995-2008). ${ }^{23}$ Hence, we can compute the number of advanced imaging (computerised tomography and magnetic resonance imaging) procedures and the number of standard imaging procedures (all other diagnostic imaging procedures) performed, by demographic group (gender/age group), region, ${ }^{24}$ and year. ${ }^{25}$ The GRIM (General Record of Incidence of Mortality) books ${ }^{26}$ published by the Australian Institute of Health and Welfare contain data on population and number of deaths, by demographic group (gender/age group), region, and year. Hence, we can computer the following variables, for 20 gender-age groups, 5 regions, and 10 years:

N_ADV_IMAGE grt $_{\text {_ }}=$ the number of advanced imaging procedures performed on members of gender-age group $\mathrm{g}$ in region $\mathrm{r}$ in year $\mathrm{t}$

N_STD_IMAGE grt $_{\text {_ }}=$ the number of standard imaging procedures performed on members of gender-age group $\mathrm{g}$ in region $\mathrm{r}$ in year $\mathrm{t}$

$\mathrm{POP}_{\text {grt }}=$ the population of gender-age group $\mathrm{g}$ in state $\mathrm{s}$ in year $\mathrm{t}$

N_DEATHS ${ }_{\text {grt }}=$ the number of deaths in gender-age group $g$ in region $\mathrm{r}$ in year $\mathrm{t}$

These data enable us to estimate difference-in-difference models of the effect of advanced imaging innovation on age-specific mortality rates. We will estimate several different model specifications. The first two will be estimated at the national level, by aggregating the regional data. The first specification is:

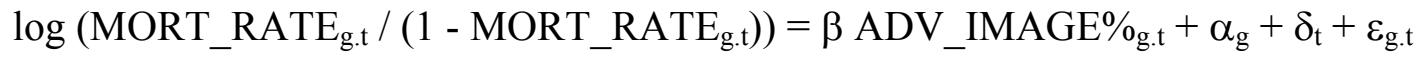

where

\footnotetext{
${ }^{23}$ https://www.medicareaustralia.gov.au/statistics/mbs_group.shtml

24 Australia consists of eight states, and the MRI procedure data are aggregated to five regions.

${ }^{25}$ Medicare Australia also publishes data on prescription drug utilization by state and year, but not by demographic group.

${ }^{26}$ http://www.aihw.gov.au/mortality/data/grim_books.cfm
} 


$$
\begin{aligned}
& \text { MORT_RATE }{ }_{g . t}=\sum_{\mathrm{r}} \mathrm{N}_{-} \text {DEATHS } \mathrm{grt}_{\mathrm{rt}} / \sum_{\mathrm{r}} \mathrm{POP}_{\mathrm{grt}}=\text { the mortality rate of group } \mathrm{g} \text { in } \\
& \text { ADV_IMAGE } \%_{\text {g.t }}=\sum_{\mathrm{r}} \text { N_ADV_IMAGE }{ }_{\text {grt }} /\left(\sum_{\mathrm{r}} \mathrm{N} \_\mathrm{ADV} \text { IMAGE }{ }_{\text {grt }}+\right. \\
& \left.\sum_{\mathrm{r}} \text { N_STD_IMAGE }{ }_{\text {grt }}\right)=\text { the fraction of imaging procedures } \\
& \text { performed on members of demographic group } g \text { in year } t \text { that were } \\
& \text { advanced procedures }
\end{aligned}
$$

In this specification, diagnostic imaging innovation is measured in the same way as it was measured in our models of U.S. life expectancy and per capita medical expenditure.

This specification may be less appropriate when analyzing data on a panel of demographic groups than when analyzing data on a panel of regions. The effect on the mortality rate of an increase in the fraction of procedures that are advanced procedures is likely to be greater, the larger the number of procedures per capita. As shown in Figure 11 , there is enormous variation across age groups in the number of diagnostic imaging services performed per 100,000 population. ${ }^{27}$ In light of this, a more appropriate specification is likely to be:

$\log \left(\right.$ MORT_RATE $_{\text {g.t }} /\left(1-\right.$ MORT_RATE $\left.\left._{\text {g.t }}\right)\right)=\beta_{\mathrm{A}}\left(\sum_{\mathrm{r}} \mathrm{N}_{-}\right.$ADV_IMAGE ${ }_{\text {grt }} / \sum_{\mathrm{r}} \mathrm{POP}$ grt $)$

$$
+\beta_{\mathrm{S}}\left(\sum_{\mathrm{r}} \mathrm{N}_{-} \mathrm{STD} \mathrm{IMAGE}_{\mathrm{grt}} / \sum_{\mathrm{r}} \mathrm{POP}_{\mathrm{grt}}\right)+\alpha_{\mathrm{g}}+\delta_{\mathrm{t}}+\varepsilon_{\mathrm{g} . \mathrm{t}}
$$

We will also estimate analogous models using data by demographic group, region, and year, including fixed region-year interaction effects as well as fixed demographic group effects:

$\log \left(\right.$ MORT_RATE $E_{\text {grt }} /(1-$ MORT_RATE $\left.g r t)\right)=\beta$ ADV_IMAGE\%grt $+\alpha_{g}+\delta_{\text {rt }}+\varepsilon_{\text {grt }}$

$\log \left(\right.$ MORT_RATE $g r t /\left(1-\right.$ MORT_RATE $\left.\left._{\text {grt }}\right)\right)=\beta_{\mathrm{A}}\left(\mathrm{N}_{-} \mathrm{ADV} \_\mathrm{IMAGE}\right.$ grt $\left./ \mathrm{POP}_{\mathrm{grt}}\right)$

$$
+\beta_{\mathrm{S}}\left(\mathrm{N} \_\mathrm{STD} \_\mathrm{IMAGE} \text { grt } / \mathrm{POP}_{\mathrm{grt}}\right)+\alpha_{\mathrm{g}}+\delta_{\mathrm{rt}}+\varepsilon_{\mathrm{grt}}
$$

Estimates of the parameters of eqs. _-_ are shown in Table 9. Line 1 shows the estimate of the ADV_IMAGE\% coefficient based on nation-level data. It has the expected negative sign but is not statistically significant. Lines 2-3 show the estimates of the coefficients of eq. ( ). The coefficient on the number of advanced imaging procedures

\footnotetext{
${ }^{27}$ There is much less variation in procedure intensity across regions.
} 
per capita is negative and significant, while the coefficient on the number of standard imaging procedures per capita is insignificant. This indicates that demographic groups that had above-average increases in the number of advanced imaging procedures per capita had above-average declines in mortality rates, but that changes in mortality rates were uncorrelated across demographic groups with changes in the number of standard imaging procedures per capita.

Figure 12 illustrates the relationship across demographic groups between the 1995-2004 increase in the number of advanced imaging procedures per capita and the 1995-2004 reduction in the log of the mortality rate. Groups below age 35 are excluded; these jointly accounted for less than $5 \%$ of deaths in 2004 . For both genders, the age profiles of the increase in the number of advanced imaging procedures per capita and the reduction in the $\log$ of the mortality rate have inverted- $U$ shapes, and are at a maximum in the 65-74 year age group.

The estimate of the coefficient of (N_ADV_IMAGE / POP) in line 2 implies that the increase in the number of advanced imaging procedures per capita accounted for about $46 \%$ of the decline in the age-adjusted Australian mortality rate during the period 1995-2005. Due to data limitations, we are unable to control for other potential determinants of mortality, such as drug vintage, physician quality, and behavioral risk factors. Since these data are available for the U.S., we can calculate the effect of controlling for these other variables on the estimate of the effect of diagnostic imaging innovation on longevity. As shown in Table 7, the coefficient on adv_image \% in Model 1 , controlling for the other included variables, is 6.463. This implies that increased use of diagnostic imaging innovation increased U.S. life expectancy by 0.62 years during 19912004: $26 \%$ of the total increase. If we estimate Model 1 excluding variables other than adv_image $\%$, the coefficient on this variable is $11.102(\mathrm{Z}=2.88$; $\mathrm{p}$-value $=0.0040)$. This would imply that increased use of diagnostic imaging innovation increased U.S. life expectancy by 1.06 years during 1991-2004: 45\% of the total increase. The latter is almost identical to our estimate based on Australian data. Therefore it seems reasonable to conclude that controlling for the other variables included in the model of U.S. life expectancy would reduce the estimate of the coefficient of (N_ADV_IMAGE / POP) by about $40 \%$, which would imply that increased use of diagnostic imaging innovation 
accounted for $26 \%$ of the total increase in Australian life expectancy during the period $1995-2004 .^{28}$

The estimates based on region-level data, shown in lines 4-6 of Table 9, are similar to the estimates based on nation-level data. The region-level estimate of the ADV_IMAGE\% coefficient (line 4) is also insignificant. The region-level coefficient on the number of advanced imaging procedures per capita (line 5) is negative and significant, and its magnitude is close to the nation-level estimate (line 2). The regionlevel coefficient on the number of standard imaging procedures per capita is positive and significant. This indicates that demographic groups that had above-average increases in the number of standard imaging procedures per capita had below-average declines in mortality rates. Groups that had above-average increases in the number of standard imaging procedures per capita may have experienced unobserved negative health shocks.

\section{Summary}

The rate of increase of longevity has varied considerably across U.S. states since 1991. This paper has examined the effect of the quality of medical care, behavioral risk factors, and other variables on life expectancy and medical expenditure using longitudinal state-level data.

We examined the effects of three different measures of the quality of medical care. The first is the average quality of diagnostic imaging procedures, defined as the fraction of procedures that are advanced procedures. The second is the average quality of practicing physicians, defined as the fraction of physicians that were trained at top-ranked medical schools. The third is the mean vintage (FDA approval year) of outpatient and inpatient prescription drugs.

We also examined the effects on longevity of three important behavioral risk factors - obesity, smoking, and AIDS incidence - and other variables - education, income, and health insurance coverage - that might be expected to influence longevity growth. Our econometric approach controlled for the effects of unobserved factors that

\footnotetext{
${ }^{28}$ Australian life expectancy has been increasing faster than U.S. life expectancy. Between 1995 and 2003, Australian life expectancy increased 2.4 years, from 77.9 to 80.3 years, while U.S. life expectancy increased 1.8 years, from 75.7 to 77.5 years. Source: OECD Health Database.
} 
vary across states but are relatively stable over time (e.g. climate and environmental quality), and unobserved factors that change over time but are invariant across states (e.g. changes in Federal government policies).

Our indicators of the quality of diagnostic imaging procedures, drugs, and physicians almost always had positive and statistically significant effects on life expectancy. Life expectancy increased more rapidly in states where (1) the fraction of Medicare diagnostic imaging procedures that were advanced procedures increased more rapidly; (2) the vintage of self- and provider-administered drugs increased more rapidly; and (3) the quality of medical schools previously attended by physicians increased more rapidly.

Between 1991 and 2004, life expectancy at birth increased 2.37 years. The estimates imply that, during this period, the increased use of advanced imaging technology increased life expectancy by $0.62-0.71$ years, use of newer outpatient prescription drugs increased life expectancy by 0.96-1.26 years, and use of newer provider-administered drugs increased life expectancy by $0.48-0.54$ years. The decline in the average quality of medical schools previously attended by physicians reduced life expectancy by $0.28-0.47$ years.

The rise from $44 \%$ to $59 \%$ in the fraction of the population that was overweight or obese reduced the increase in life expectancy by .58-.68 years. The decline in the incidence of AIDS is estimated to have increased life expectancy by .18-.20 years. The small decline in smoking prevalence may have increased life expectancy by about 0.10 years.

Growth in life expectancy was uncorrelated across states with health insurance coverage and education, and inversely correlated with per capita income growth. The $19 \%$ increase in real per capita income is estimated to have reduced life expectancy by .34-.43 years. The sum of the contributions of all of the factors to the increase in life expectancy is in the 0.85-1.32 year range. Consequently, between 1.05 and 1.52 years of the 2.37-year increase in life expectancy is unexplained.

Although states with larger increases in the quality of diagnostic procedures, drugs, and physicians had larger increases in life expectancy, they did not have larger increases in per capita medical expenditure. This may be the case because, while newer 
diagnostic procedures and drugs are more expensive than their older counterparts, they may reduce the need for costly additional medical treatment. The absence of a correlation across states between medical innovation and expenditure growth is inconsistent with the view that advances in medical technology have contributed to rising overall U.S. health care spending. Increased health insurance coverage is associated with lower growth in per capita medical expenditure.

The availability of data from Australia's universal health care system, Medicare Australia, allowed us to provide some additional evidence about the impact of advanced imaging technology on mortality. We estimated difference-in-difference models of the effect of advanced imaging innovation on age-specific mortality rates. Demographic groups that had above-average increases in the number of advanced imaging procedures per capita had above-average declines in mortality rates, but changes in mortality rates were uncorrelated across demographic groups with changes in the number of standard imaging procedures per capita. Estimates of the effect of diagnostic imaging innovation on longevity based on Australian data are quite consistent with estimates based on U.S. data. 


\section{References}

Arias E. (2006), United States life tables, 2003. National vital statistics reports; vol 54 no 14. Hyattsville, MD: National Center for Health Statistics. http://www.cdc.gov/nchs/data/nvsr/nvsr54/nvsr54_14.pdf

Bahk, Byong-Hyong and Michael Gort (1993), "Decomposing Learning by Doing in New Plants," Journal of Political Economy, 101, 561-583.

Baltagi, Badi H. \& Rich, Daniel P. (2005), "Skill-biased technical change in US manufacturing: a general index approach," Journal of Econometrics 126(2), pages 549570, June.

Bartel, Ann P., and Frank R. Lichtenberg (1987), "The Comparative Advantage of Educated Workers in Implementing New Technology," Review of Economics and Statistics 69(1), Feb., 1-11.

Bils, Mark (2004), "Measuring the Growth from Better and Better Goods," NBER working paper no. 10606, July, http://www.nber.org/papers/w10606.

Boucekkine, Raouf, David de la Croix, and Omar Licandro, "Vintage Capital," Department of Economics, European University Institute, Eco No. 2006/08 http://cadmus.iue.it/dspace/bitstream/1814/4346/1/ECO2006-8.pdf

Bresnahan, Timothy F., and Robert J. Gordon (1996), The Economics of New Goods (Chicago: University of Chicago Press).

Duggan, Mark G., and William N. Evans (2008) "Estimating the Impact of Medical Innovation: A Case Study of HIV Antiretroviral Treatments," Forum for Health Economics \& Policy: Vol. 11: Iss. 2 (Economics of the HIV Epidemic), Article 1. http://www.bepress.com/fhep/11/2/1

Fang, Hanming, and Alessandro Gavazza (2007), "Dynamic Inefficiencies in Employment-Based Health Insurance System Theory and Evidence", National Bureau of Economic Research Working Paper 13371, September, http://www.nber.org/papers/w13371

Gerdtham, Ulf-G, and Bengt Jonsson (2000), "International comparisons of health expenditure: theory, data and econometric analysis," in Handbook of Health Economics vol. 1, ed. by A. J. Culyer and J. P. Newhouse, pp. 11-53.

Grossman, Gene M., and Elhanan Helpman (1993), Innovation and Growth in the Global Economy (Cambridge: MIT Press).

Hulten, Charles R. (1992), "Growth accounting when technical change is embodied in capital,” The American Economic Review, Vol. 82, No. 4. (Sep., 1992), pp. 964-980. 
Hupfeld, Stefan (2008), "Non-Monotonicity in the Longevity-Income-Relationship," working paper, Department of Economics, University of Konstanz, Germany, August 14, http://wipol.wiwi.uni-konstanz.de/lehrstuhl/personen/hupfeld_non_monotinicity.pdf

Jones, Charles (1998), Introduction to Economic Growth (New York: Norton).

Kaiser Family Foundation, "How Changes in Medical Technology Affect Health Care Costs," March 2007, http://www.kff.org/insurance/snapshot/chcm030807oth.cfm\#front5

Kopp, Raymond J., and V. Kerry Smith (1985), “The Measurement of Non-Neutral Technological Change," International Economic Review, Vol. 26, No. 1 (Feb.), pp. 135159.

Lai, D.J., P.M. Tarwatera, and R.J. Hardy (2006), "Measuring the impact of HIV/AIDS, heart disease and malignant neoplasms on life expectancy in the USA from 1987 to 2000," Public Health 120, 486-492.

Lichtenberg, Frank (2005a), "Pharmaceutical knowledge-capital accumulation and longevity," in Measuring capital in the new economy, ed. by Carol Corrado, John Haltiwanger, and Dan Sichel, 237-269 (University of Chicago Press).

Lichtenberg, Frank (2005b), The impact of new drug launches on longevity: evidence from longitudinal disease-level data from 52 countries, 1982-2001, International Journal of Health Care Finance and Economics 5, 47-73.

Lichtenberg, Frank (2005c), "Availability of new drugs and Americans' ability to work," Journal of Occupational and Environmental Medicine 47 (4), April, 373-380.

Lichtenberg, Frank (2005d), "The Effect of Access Restrictions on the Vintage of Drugs Used by Medicaid Enrollees," American Journal of Managed Care 11, Special Issue, SP7-SP13.

Lichtenberg, Frank (2006), "The effect of using newer drugs on admissions of elderly Americans to hospitals and nursing homes: state-level evidence from 1997-2003," Pharmacoeconomics,

Miller, Richard D., and H. E. Frech (1999), The Productivity of Health Care and Pharmaceuticals: an International Comparison, (Washington, DC: American Enterprise Institute).

Murray CJL, Kulkarni SC, Michaud C, Tomijima N, Bulzacchelli MT, et al. (2006), "Eight Americas: Investigating mortality disparities across races, counties, and race counties in the United States," PLoS Med 3(9): e260.

Murphy, Kevin M., and Robert H. Topel (2005), "The Value of Health and Longevity," June, NBER Working Paper No. W11405. 
National Science Foundation, U.S. Corporate R\&D: Volume 1: Top 500 Firms in R\&D by Industry Category, http://www.nsf.gov/statistics/nsf00301/expendit.htm.

Nordhaus, William D., "The Health of Nations: The Contribution of Improved Health to Living Standards" (March 2002). NBER Working Paper No. W8818. Available at SSRN: http://ssrn.com/abstract=302579

Rettig, Richard A., "Medical Innovation Duels Cost Containment," Health Affairs (Summer 1994): 15.

Ruhm ${ }_{2}$ Christopher J. (2004), "Macroeconomic Conditions, Health and Mortality," NBER Working Paper No. W11007, December, http://www.nber.org/papers/w11007

Sakellaris, Plutarchos and Dan Wilson (2001), The production-side approach to estimating embodied technological change. Finance and Economics Discussion Series 2001-20, Board of Governors of the Federal Reserve System.

Sakellaris, Plutarchos and Dan Wilson (2004), "Quantifying Embodied Technological Change," Review of Economic Dynamics 7(1), pp. 1-26.

Skinner, Jonathan, and Douglas Staiger (2005), "Technology adoption from hybrid corn to beta blockers," National Bureau of Economic Research Working Paper No. 11251, March http://www.nber.org/papers/w11251.

Solow R. (1960), "Investment and technological progress," in K. Arrow, S. Karlin and P. Suppes (eds.), Mathematical Methods in Social Sciences 1959, 89.104. Stanford University Press.

Uchida, Eiichi, Shunichi Araki and Katsuyuki Murata (1992), "Socioeconomic factors affecting the longevity of the Japanese population: a study for 1980 and 1985," Journal of Biosocial Science 24, 497-504.

U.S. Dept. of Veterans Affairs (2007), Pharmacy Benefits Management Strategic Healthcare Group, National Drug File, http://www.pbm.va.gov/NationalFormulary.aspx

Wennberg, John (2006), The Care of Patients with Severe Chronic Illness: A Report on the Medicare Program, The Dartmouth Atlas of Health Care 2006 (Hanover, NH: Dartmouth Medical School Center for the Evaluative Clinical Sciences), http://www.dartmouthatlas.org/atlases/2006 Chronic Care Atlas.pdf 
Table 1

Research ranking and primary care ranking of top 20 medical schools, ranked by research ranking

\begin{tabular}{|l|r|r|}
\hline \multicolumn{1}{|c|}{ School } & $\begin{array}{c}\text { research } \\
\text { rank }\end{array}$ & $\begin{array}{c}\text { primary } \\
\text { care } \\
\text { rank }\end{array}$ \\
\hline Harvard University (MA) & 1 & 13 \\
\hline Johns Hopkins University (MD) & 2 & 28 \\
\hline University of Pennsylvania & 3 & 16 \\
\hline Washington University in St. Louis & 4 & 38 \\
\hline University of California-San Francisco & 5 & 8 \\
\hline University of Washington & 7 & 1 \\
\hline Stanford University (CA) & 8 & 34 \\
\hline Duke University (NC) & 8 & 11 \\
\hline Yale University (CT) & 10 & 45 \\
\hline Baylor College of Medicine (TX) & 10 & 57 \\
\hline University of Michigan-Ann Arbor & 10 & 18 \\
\hline Columbia U. College of Physicians and Surgeons (NY) & 13 & 38 \\
\hline University of California-Los Angeles (Geffen) & 14 & 18 \\
\hline University of California-San Diego & 15 & 53 \\
\hline University of Pittsburgh & 15 & 30 \\
\hline University of Chicago (Pritzker) & 15 & 18 \\
\hline Cornell University (Weill) (NY) & 19 & 20 \\
\hline Vanderbilt University (TN) & & 2 \\
\hline U. of Texas Southwestern Medical Center-Dallas & 5 \\
\hline University of North Carolina-Chapel Hill & & 18 \\
\hline
\end{tabular}

Source: U.S. News and World Report 
Table 2

Percent of physicians who were graduates of top-ranked medical schools, 1991-2004

\begin{tabular}{|c|c|c|c|}
\hline Year & $\begin{array}{c}\text { Number of } \\
\text { physicians }\end{array}$ & $\begin{array}{c}\text { \% of physicians who were } \\
\text { graduates from top 60 } \\
\text { medical schools ranked in } \\
\text { terms of research }\end{array}$ & $\begin{array}{c}\text { \% of physicians who were } \\
\text { graduates from top 60 } \\
\text { medical schools ranked in } \\
\text { terms of primary care }\end{array}$ \\
\hline 1991 & 582,910 & $45.2 \%$ & $40.0 \%$ \\
\hline 1992 & 596,337 & $44.7 \%$ & $39.7 \%$ \\
\hline 1993 & 590,583 & $44.7 \%$ & $40.0 \%$ \\
\hline 1994 & 640,044 & $44.1 \%$ & $39.5 \%$ \\
\hline 1995 & 647,064 & $43.7 \%$ & $39.3 \%$ \\
\hline 1996 & 664,096 & $43.6 \%$ & $39.2 \%$ \\
\hline 1997 & 681,343 & $43.5 \%$ & $39.2 \%$ \\
\hline 1998 & 713,856 & $42.9 \%$ & $38.8 \%$ \\
\hline 1999 & 743,261 & $42.4 \%$ & $38.4 \%$ \\
\hline 2000 & 756,868 & $42.5 \%$ & $38.6 \%$ \\
\hline 2001 & 771,381 & $42.1 \%$ & $38.3 \%$ \\
\hline 2002 & 791,496 & $41.6 \%$ & $38.0 \%$ \\
\hline 2003 & 810,648 & $41.4 \%$ & $37.8 \%$ \\
\hline 2004 & 818,732 & $41.0 \%$ & $37.5 \%$ \\
\hline
\end{tabular}


Table 3

Distribution and vintage of Medicaid prescriptions in 1991 and 2004, by major therapeutic class

\begin{tabular}{|c|c|c|c|c|}
\hline \multirow[t]{2}{*}{\begin{tabular}{|l|} 
Major therapeutic class \\
\end{tabular}} & \multicolumn{2}{|c|}{ share of rx's } & \multicolumn{2}{|c|}{ Mean vintage } \\
\hline & 1991 & 2004 & 1991 & 2004 \\
\hline central nervous system medications & $19 \%$ & $29 \%$ & 1967.6 & 1984.1 \\
\hline cardiovascular medications & $21 \%$ & $21 \%$ & 1975.6 & 1982.1 \\
\hline antimicrobials & $16 \%$ & $9 \%$ & 1970.4 & 1982.2 \\
\hline hormones/synthetics/modifiers & $7 \%$ & $8 \%$ & 1971.6 & 1978.2 \\
\hline gastrointestinal medications & $5 \%$ & $6 \%$ & 1978.4 & 1993.8 \\
\hline respiratory tract medications & $7 \%$ & $6 \%$ & 1976.6 & 1986.6 \\
\hline musculoskeletal medications & $7 \%$ & $4 \%$ & 1975.6 & 1987.5 \\
\hline antihistamines & $3 \%$ & $3 \%$ & 1953.7 & 1976.4 \\
\hline dermatological agents & $5 \%$ & $3 \%$ & 1968.7 & 1972.8 \\
\hline blood products/modifiers/volume expanders & $1 \%$ & $2 \%$ & 1956.3 & 1986.7 \\
\hline ophthalmic agents & $2 \%$ & $2 \%$ & 1972.3 & 1988.6 \\
\hline nasal and throat agents,topical & $1 \%$ & $2 \%$ & 1974.1 & 1984.7 \\
\hline autonomic medications & $2 \%$ & $1 \%$ & 1961.0 & 1974.3 \\
\hline therapeutic nutrients/minerals/electrolytes & $2 \%$ & $1 \%$ & 1971.2 & 1972.4 \\
\hline genitourinary medications & $1 \%$ & $1 \%$ & 1977.4 & 1980.9 \\
\hline vitamins & $0 \%$ & $1 \%$ & 1952.1 & 1962.3 \\
\hline antineoplastics & $0 \%$ & $0 \%$ & 1969.8 & 1976.3 \\
\hline immunological agents & $0 \%$ & $0 \%$ & 1976.0 & 1992.0 \\
\hline dental and oral agents,topical & $0 \%$ & $0 \%$ & 1962.6 & 1972.3 \\
\hline antiparasitics & $1 \%$ & $0 \%$ & 1976.2 & 1972.7 \\
\hline antidotes,deterrents and poison control & $0 \%$ & $0 \%$ & 1967.5 & 1975.6 \\
\hline pharmaceutical aids/reagents & $0 \%$ & $0 \%$ & 1972.1 & 1971.5 \\
\hline irrigation/dialysis solutions & $0 \%$ & $0 \%$ & 1968.9 & 1969.2 \\
\hline otic agents & $0 \%$ & $0 \%$ & 1958.8 & 1988.5 \\
\hline rectal,local & $0 \%$ & $0 \%$ & 1959.1 & 1976.2 \\
\hline miscellaneous agents & $0 \%$ & $0 \%$ & 1950.0 & 1993.9 \\
\hline diagnostic agents & $0 \%$ & $0 \%$ & 1957.5 & 1957.1 \\
\hline prosthetics/supplies/devices & $0 \%$ & $0 \%$ & 1985.0 & 1985.0 \\
\hline
\end{tabular}

Note: therapeutic classes are ranked by share of Rx's in 2004. 
Table 4

Top 25 active ingredients contained in 2004 Medicaid prescriptions, ranked by number of prescriptions

\begin{tabular}{|l|r|}
\hline active_ingredient & number of prescriptions \\
\hline acetaminophen & $48,661,138$ \\
\hline hydrochlorothiazide & $35,027,596$ \\
\hline risperidone & $31,534,553$ \\
\hline levothyroxine sodium & $29,278,356$ \\
\hline amoxicillin (as trihydrate) & $26,065,616$ \\
\hline hydrocodone bitartrate & $25,832,307$ \\
\hline clonazepam & $16,976,543$ \\
\hline ethinyl estradiol & $16,452,694$ \\
\hline clavulanate potassium & $16,295,635$ \\
\hline fluticasone propionate & $15,435,753$ \\
\hline clarithromycin & $13,826,324$ \\
\hline lisinopril & $13,678,282$ \\
\hline verapamil hydrochloride & $13,241,735$ \\
\hline amitriptyline hydrochloride & $12,650,203$ \\
\hline erythromycin ethylsuccinate & $11,849,113$ \\
\hline trandolapril & $11,730,763$ \\
\hline ranitidine hydrochloride & $11,421,621$ \\
\hline fluoxetine hydrochloride & $11,394,072$ \\
\hline metformin hydrochloride & $11,328,717$ \\
\hline furosemide & $10,908,503$ \\
\hline levofloxacin & $10,834,964$ \\
\hline ibuprofen & $10,791,720$ \\
\hline potassium chloride & $10,568,663$ \\
\hline divalproex sodium & $10,313,345$ \\
\hline paroxetine hydrochloride & $9,947,294$ \\
\hline
\end{tabular}


Table 5

Top 25 active ingredients contained in 2004 Medicare drug treatments, ranked by total services count

\begin{tabular}{|l|r|}
\hline active_ingredient & TOTAL_SERVICES_COUNT \\
\hline sodium chloride & $55,426,498$ \\
\hline mycophenolate mofetil & $47,917,499$ \\
\hline tacrolimus & $43,062,403$ \\
\hline heparin & $36,659,665$ \\
\hline oxaliplatin & $27,314,244$ \\
\hline cyclosporine & $21,892,673$ \\
\hline dexamethasone sodium phosphate & $19,764,089$ \\
\hline botulinum toxin type A & $14,661,255$ \\
\hline prednisone & $10,913,119$ \\
\hline infliximab & $9,943,030$ \\
\hline imiglucerase & $9,010,483$ \\
\hline triamcinolone acetonide & $7,856,756$ \\
\hline alpha-1 proteinase inhibitor & $6,631,202$ \\
\hline dolasetron mesylate & $6,215,073$ \\
\hline dextrose & $6,185,437$ \\
\hline sirolimus & $5,822,688$ \\
\hline bacteriostats & $5,507,020$ \\
\hline granisetron hydrochloride & $5,324,628$ \\
\hline cyanocobalamin & $5,247,190$ \\
\hline ondansetron hydrochloride & $5,223,916$ \\
\hline Rh0 (d) immune globulin human & $4,845,732$ \\
\hline methylprednisolone acetate & $4,543,014$ \\
\hline iron sucrose & $4,454,117$ \\
\hline morphine sulfate & $4,042,780$ \\
\hline leucovorin calcium & $3,787,017$ \\
\hline
\end{tabular}


Table 6

Population-weighted means of key variables, by year

\begin{tabular}{|c|c|c|c|c|c|c|c|c|c|c|c|c|c|c|c|}
\hline $\begin{array}{l}\tilde{\Xi} \\
\grave{\nu}\end{array}$ & 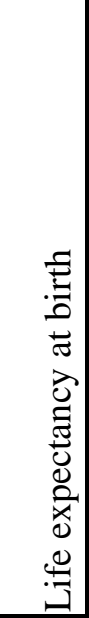 & 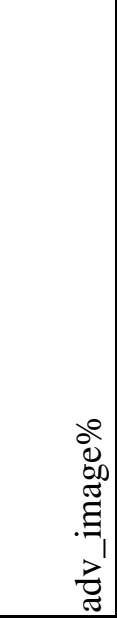 & 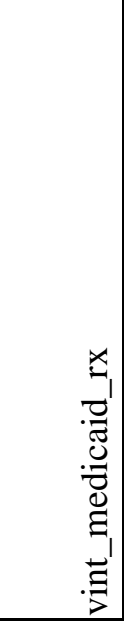 & 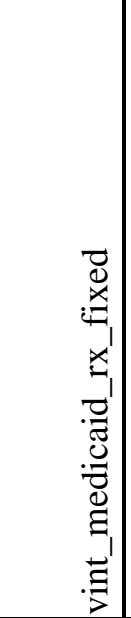 & 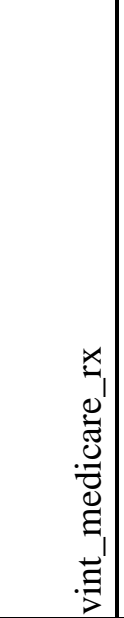 & 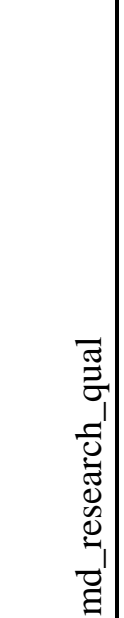 & 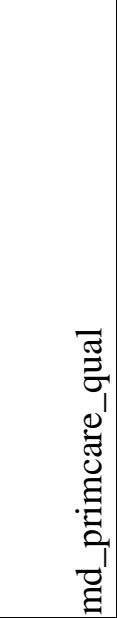 & 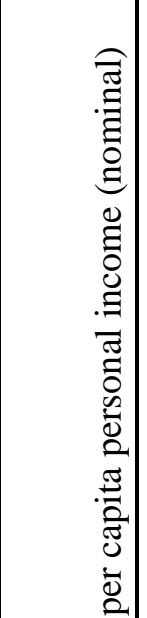 & 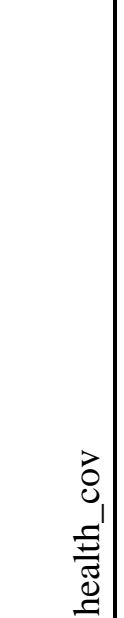 & 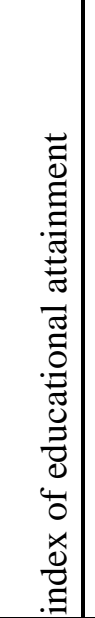 & 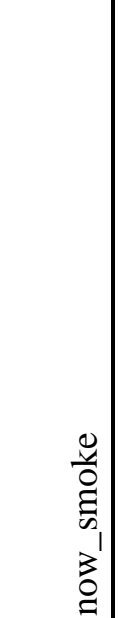 & 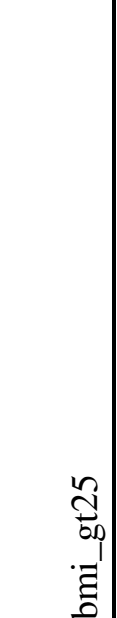 & : & 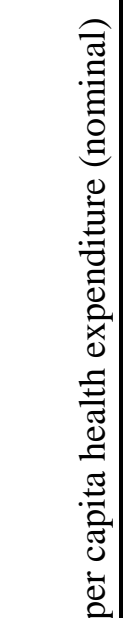 & 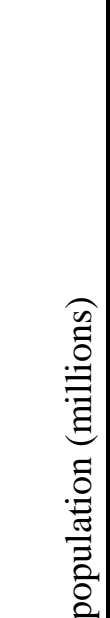 \\
\hline 1991 & 75.5 & $9.3 \%$ & 1971.4 & 1971.2 & 1973.6 & $45.5 \%$ & $41.4 \%$ & \begin{tabular}{|l|}
19,743 \\
\end{tabular} & $86.1 \%$ & \begin{tabular}{l|l}
4.53 \\
\end{tabular} & $23.8 \%$ & $44.5 \%$ & 16.9 & $\$ 2,634$ & 241.8 \\
\hline 1992 & 75.8 & $9.5 \%$ & 1971.7 & 1971.6 & 1975.2 & $44.9 \%$ & $41.1 \%$ & $\$ 20,715$ & $85.8 \%$ & 4.55 & $23.1 \%$ & $6.4 \%$ & 18.9 & 2,819 & 45.0 \\
\hline 1993 & 75.6 & $9.6 \%$ & 1972.1 & 1972.2 & 1976.6 & $44.9 \%$ & $41.4 \%$ & \begin{tabular}{|l|}
$\$ 21,216$ \\
\end{tabular} & $87.1 \%$ & 4.58 & $22.6 \%$ & $47.3 \%$ & 23.1 & $\$ 2,942$ & 241.3 \\
\hline 1994 & 75.8 & $9.6 \%$ & 1972.6 & 1972.9 & 1980.1 & $44.4 \%$ & $40.9 \%$ & $\$ 22,074$ & $86.9 \%$ & \begin{tabular}{l|l|}
4.52 \\
\end{tabular} & $22.4 \%$ & $48.4 \%$ & 29.7 & $\$ 3,080$ & 256.4 \\
\hline 1995 & 75.9 & $9.8 \%$ & 1973.2 & 1973.6 & 1981.5 & $44.1 \%$ & $40.7 \%$ & $\$ 23,012$ & $87.7 \%$ & 4.57 & $22.2 \%$ & $49.4 \%$ & 29.7 & $\$ 3,225$ & 254.0 \\
\hline 1996 & 76.3 & $10.4 \%$ & 1974.1 & 1974.6 & 1982.8 & $44.0 \%$ & $40.7 \%$ & $\$ 24,111$ & $86.7 \%$ & 4.64 & $23.2 \%$ & $50.3 \%$ & 27.1 & $\$ 3,360$ & 256.9 \\
\hline 1997 & 76.6 & $11.3 \%$ & 1975.1 & 1975.9 & 1983.4 & $43.9 \%$ & $40.6 \%$ & $\$ 25,273$ & $86.9 \%$ & 4.65 & $22.7 \%$ & $51.3 \%$ & 25.4 & $\$ 3,502$ & 259.9 \\
\hline 1998 & 76.8 & $11.9 \%$ & 1976.1 & 1977.1 & 1985.0 & $43.4 \%$ & $40.2 \%$ & $\$ 26,815$ & $86.8 \%$ & 4.66 & $22.8 \%$ & $52.9 \%$ & 21.9 & $\$ 3,645$ & 264.7 \\
\hline 1999 & 76.8 & $12.8 \%$ & 1977.1 & 1978.4 & 1986.1 & $42.8 \%$ & $39.9 \%$ & $\$ 27,794$ & $86.9 \%$ & 4.66 & $22.6 \%$ & $54.2 \%$ & 17.4 & $\$ 3,815$ & 273.3 \\
\hline 2000 & 77.0 & $13.8 \%$ & 1978.2 & 1979.8 & 1987.2 & $42.8 \%$ & $39.9 \%$ & $\$ 29,663$ & $87.3 \%$ & 4.71 & $22.5 \%$ & $55.2 \%$ & 14.7 & $\$ 4,027$ & 276.3 \\
\hline 2001 & 77.1 & $15.1 \%$ & 1978.9 & 1980.7 & 1988.3 & $42.3 \%$ & $39.5 \%$ & $\$ 30,407$ & $87.5 \%$ & 4.73 & $22.7 \%$ & $56.7 \%$ & 13.7 & $\$ 4,332$ & 279.0 \\
\hline 2002 & 77.2 & $16.0 \%$ & 1979.7 & 1981.6 & 1989.3 & $41.9 \%$ & $39.2 \%$ & $\$ 30,661$ & $87.0 \%$ & 4.75 & $21.6 \%$ & $57.2 \%$ & 13.1 & $\$ 4,643$ & 281.7 \\
\hline 2003 & 77.4 & $16.7 \%$ & 1980.3 & 1982.4 & 1990.7 & $41.5 \%$ & $38.9 \%$ & $\$ 31,340$ & $86.9 \%$ & 4.76 & $21.2 \%$ & $58.4 \%$ & 12.1 & $\$ 4,954$ & 284.4 \\
\hline 2004 & 77.9 & $18.8 \%$ & 1980.7 & 1982.6 & 1992.2 & $41.0 \%$ & $38.5 \%$ & $\$ 32,888$ & $86.7 \%$ & 4.76 & $20.0 \%$ & $59.4 \%$ & 8.4 & $\$ 5,293$ & 287.1 \\
\hline
\end{tabular}


Table 7

Estimates of models of life expectancy and per capita personal health care expenditure

\begin{tabular}{|c|c|c|c|c|c|c|c|c|c|}
\hline \multirow[b]{3}{*}{ Independent variable } & \multicolumn{9}{|c|}{ Dependent variable: life expectancy at birth } \\
\hline & \multicolumn{3}{|c|}{ Model 1} & \multicolumn{3}{|c|}{ Model 2} & \multicolumn{3}{|c|}{ Model 3} \\
\hline & Estimate & $\mathbf{Z}$ & ProbZ & Estimate & $\mathbf{Z}$ & ProbZ & Estimate & $\mathbf{Z}$ & ProbZ \\
\hline adv_image\% & 6.463 & 2.951 & 0.003 & 6.825 & 3.176 & 0.001 & 7.446 & 3.277 & 0.001 \\
\hline vint_medicaid_rx & 0.135 & 3.965 & 0.000 & & & & & & \\
\hline \multicolumn{2}{|c|}{ vint_medicaid_rx_fixweight } & & & 0.085 & 2.806 & 0.005 & 0.095 & 2.992 & 0.003 \\
\hline vint_medicare_rx & 0.029 & 2.906 & 0.004 & 0.026 & 2.658 & 0.008 & 0.026 & 2.415 & 0.016 \\
\hline md_primcare_qual & 6.828 & 2.458 & 0.014 & 7.013 & 2.562 & 0.010 & 9.709 & 3.085 & 0.002 \\
\hline md_research_qual & 5.086 & 1.381 & 0.167 & 6.219 & 1.839 & 0.066 & & & \\
\hline bmi_gt25 & -3.869 & -2.521 & 0.012 & -4.465 & -2.823 & 0.005 & -4.532 & -2.885 & 0.004 \\
\hline aids_pop & -0.021 & -5.136 & 0.000 & -0.021 & -4.504 & 0.000 & -0.023 & -5.924 & 0.000 \\
\hline now_smoke & -1.618 & -1.074 & 0.283 & -2.181 & -1.467 & 0.142 & -2.570 & -1.716 & 0.086 \\
\hline health_cov & 0.645 & 0.483 & 0.629 & 1.356 & 1.013 & 0.311 & 1.502 & 1.135 & 0.257 \\
\hline edu & -0.004 & -0.015 & 0.988 & 0.011 & 0.046 & 0.963 & -0.039 & -0.156 & 0.876 \\
\hline \multirow[t]{3}{*}{ income } & -1.834 & -1.879 & 0.060 & -2.070 & -2.223 & 0.026 & -2.272 & -2.221 & 0.026 \\
\hline & \multicolumn{9}{|c|}{ Dependent variable: log of per capita personal health care expenditure } \\
\hline & \multicolumn{3}{|c|}{ Model 4} & \multicolumn{3}{|c|}{ Model 5} & \multicolumn{3}{|c|}{ Model 6} \\
\hline Independent variable & Estimate & $\mathbf{Z}$ & ProbZ & Estimate & $\mathbf{Z}$ & ProbZ & Estimate & $\mathbf{Z}$ & ProbZ \\
\hline adv_image\% & 0.377 & 1.413 & 0.158 & 0.379 & 1.411 & 0.158 & 0.336 & 1.345 & 0.179 \\
\hline vint_medicaid_rx & -0.003 & -0.458 & 0.647 & & & & & & \\
\hline \multicolumn{2}{|c|}{ vint_medicaid_rx_fixweight } & & & -0.004 & -0.972 & 0.331 & -0.005 & -1.197 & 0.231 \\
\hline vint_medicare_rx & -0.001 & -1.136 & 0.256 & -0.001 & -1.071 & 0.284 & -0.001 & -1.070 & 0.285 \\
\hline md_primcare_qual & -0.420 & -0.939 & 0.348 & -0.436 & -0.994 & 0.320 & & & \\
\hline md_research_qual & 0.209 & 0.424 & 0.672 & 0.232 & 0.468 & 0.640 & 0.043 & 0.097 & 0.923 \\
\hline bmi_gt25 & 0.078 & 0.658 & 0.510 & 0.095 & 0.774 & 0.439 & 0.100 & 0.823 & 0.410 \\
\hline aids_pop & 0.002 & 2.048 & 0.041 & 0.002 & 2.005 & 0.045 & 0.002 & 2.080 & 0.038 \\
\hline now_smoke & 0.261 & 1.200 & 0.230 & 0.272 & 1.187 & 0.235 & 0.300 & 1.320 & 0.187 \\
\hline health_cov & -0.403 & -2.042 & 0.041 & -0.397 & -1.864 & 0.062 & -0.407 & -1.984 & 0.047 \\
\hline edu & 0.101 & 2.344 & 0.019 & 0.103 & 2.408 & 0.016 & 0.106 & 2.484 & 0.013 \\
\hline income & 0.256 & 1.692 & 0.091 & 0.252 & 1.650 & 0.099 & 0.267 & 1.761 & 0.078 \\
\hline
\end{tabular}

The estimates are weighted least-squares estimates, weighting by state population. All equations include fixed state effects and fixed year effects. Standard errors are clustered within states. 
Table 8

Calculation of the 1991-2004 change in life expectancy that was attributable to various factors

\begin{tabular}{|l|c|c|c|c|}
\hline & & \multicolumn{3}{|c|}{$\begin{array}{r}\text { Estimated effect of change on } \\
\text { 1991-2004 change in life } \\
\text { expectancy }\end{array}$} \\
\hline & & & & \\
\hline & change, 1991-2004 & Model 1 & Model 2 & Model 3 \\
\hline life expectancy at birth & & & & \\
\hline & 2.37 & & & \\
\hline adv_image\% & & & & 0.71 \\
\hline vint_medicaid_rx & 0.10 & 0.62 & 0.65 & \\
\hline vint_medicaid_rx_fixweight & 9.34 & 1.26 & & 1.08 \\
\hline vint_medicare_rx & 11.37 & & 0.96 & 0.48 \\
\hline md_primcare_qual & 18.56 & 0.54 & 0.49 & -0.28 \\
\hline md_research_qual & -0.03 & -0.19 & -0.20 & \\
\hline bmi_gt25 & -0.04 & -0.22 & -0.27 & \\
\hline aids_pop & 0.15 & -0.58 & -0.67 & -0.68 \\
\hline now_smoke & -8.49 & 0.18 & 0.18 & 0.20 \\
\hline health_cov & -0.04 & 0.06 & 0.08 & 0.10 \\
\hline edu & 0.01 & 0.00 & 0.01 & 0.01 \\
\hline income & 0.23 & 0.00 & 0.00 & -0.01 \\
\hline total & 0.19 & -0.34 & -0.39 & -0.43 \\
\hline & & $\mathbf{1 . 3 2}$ & $\mathbf{0 . 8 5}$ & $\mathbf{1 . 1 8}$ \\
\hline unexplained & & & & \\
\hline
\end{tabular}


Table 9

Estimates of the effect of medical imaging innovation on Australian age-specific mortality rates

\begin{tabular}{|c|c|c|c|c|c|}
\hline Line & Equation & Parameter & Estimate & $\mathbf{Z}$ & $\operatorname{Pr}>|Z|$ \\
\hline & & & & & \\
\hline & & \multirow{2}{*}{\multicolumn{4}{|c|}{ National level $(\mathrm{N}=240)$}} \\
\hline & & & & & \\
\hline & & & & & \\
\hline 1 & 2 & ADV_IMAGE\% & -1.411 & -1.180 & 0.237 \\
\hline & & & & & \\
\hline 2 & 3 & N_ADV_IMAGE / POP & -1.592 & -2.000 & 0.046 \\
\hline \multirow[t]{2}{*}{3} & 3 & N_STD_IMAGE / POP & 0.130 & 0.680 & 0.494 \\
\hline & & \multicolumn{4}{|c|}{ Regional level $(\mathrm{N}=1100)$} \\
\hline & & & & & \\
\hline 4 & 4 & ADV_IMAGE\% & -0.470 & -1.170 & 0.241 \\
\hline 5 & 5 & IN ADV IMAGE / POP & -1.493 & -3.190 & 0.001 \\
\hline 6 & 5 & N_STD_IMAGE / POP & 0.225 & 2.770 & 0.006 \\
\hline
\end{tabular}

Equations _ and _ include fixed demographic-group effects and fixed year effects. Equations _ and _ include fixed demographic-group effects and fixed region-year interaction effects. Standard errors are clustered within demographic groups. 


\section{Figure 1}

Increase in life expectancy at birth 1991-2004, by state

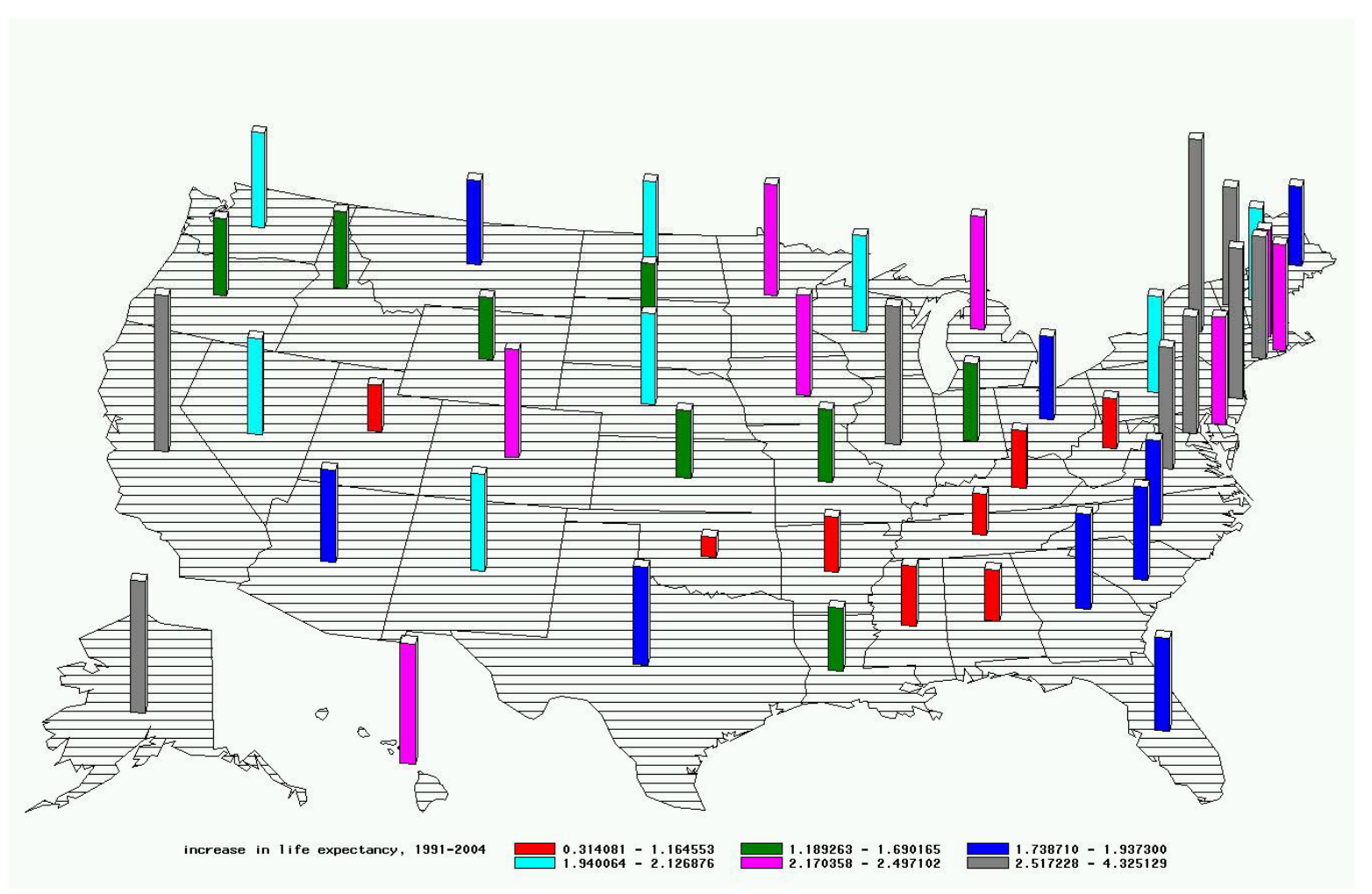


Figure 3

Number of advanced imaging procedures as \% of number of standard + advanced procedures, U.S., 1991-2004

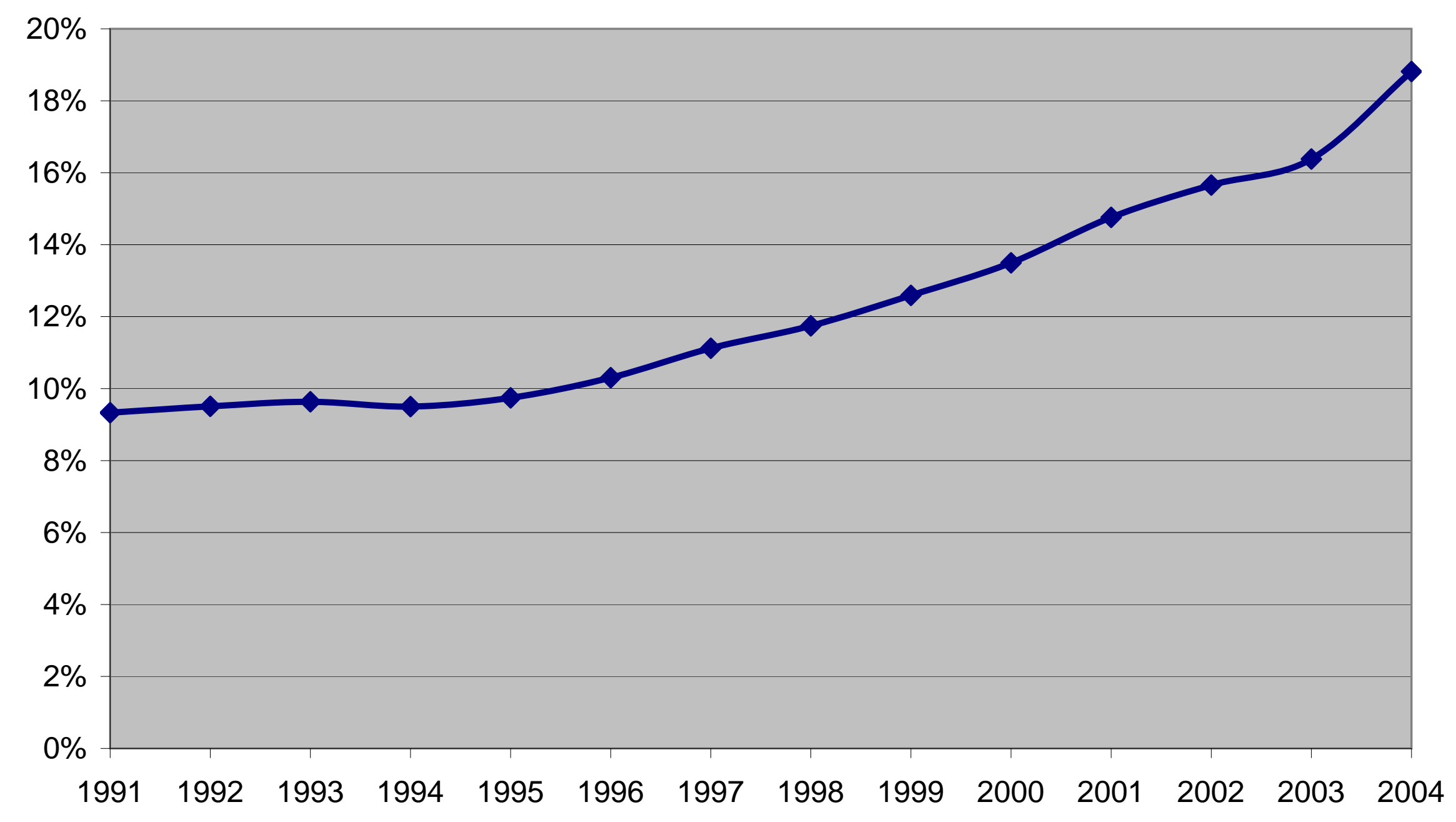




\section{Figure 4}

Number of advanced imaging procedures in 2004 as

\% of number of standard + advanced procedures in 2004

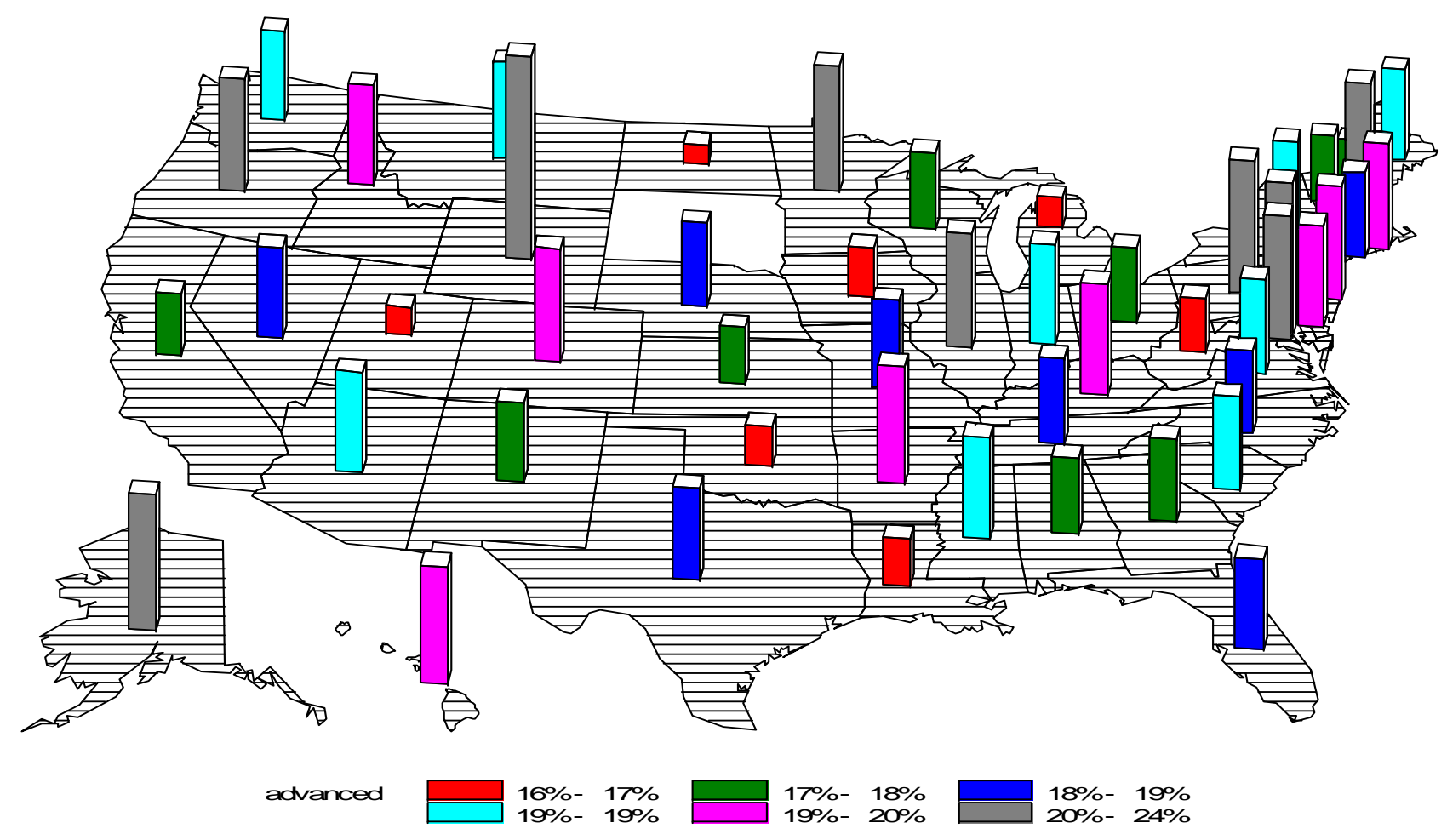




\section{Figure 5}

Fraction of practicing physicians who graduated from the top 60 medical schools ranked in terms of research, by state, 2004

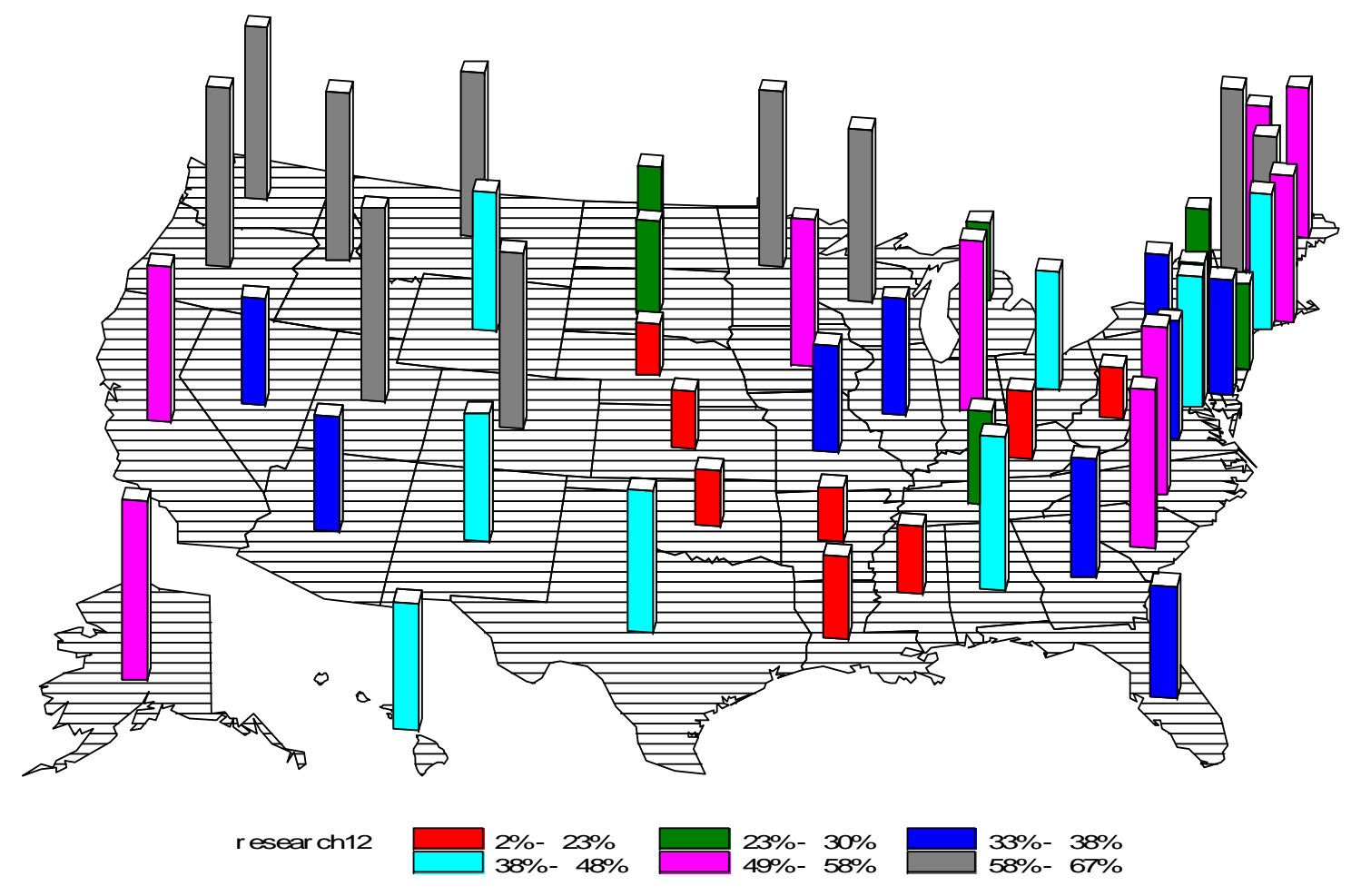




\section{Figure 6}

Fraction of practicing physicians who graduated from the top 60 medical schools ranked in terms of primary care, by state, 2004

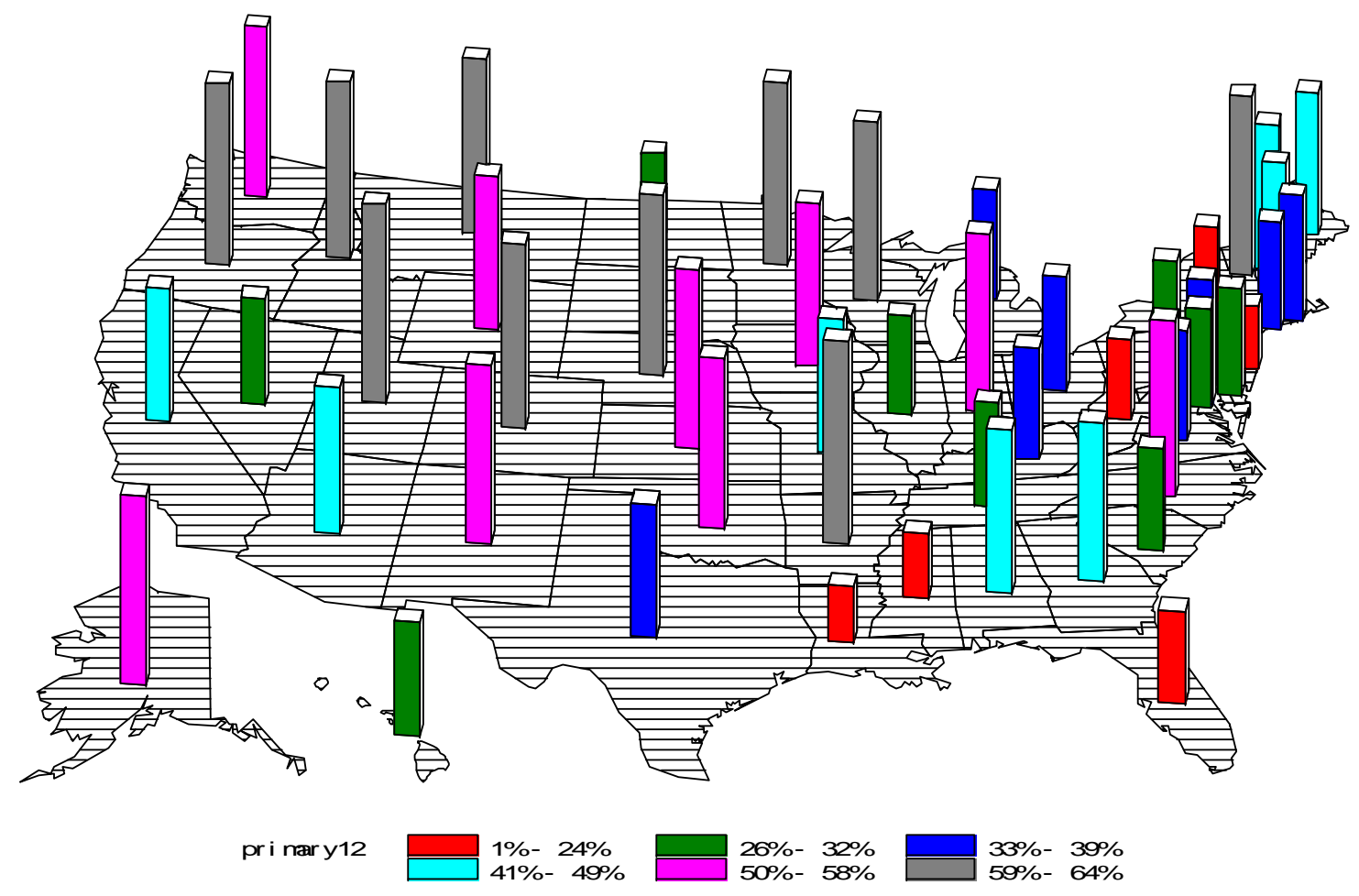




\section{Figure 7}

Annual incidence rates (cases per 100,000) of prostate and colon \& rectum cancer, males, 2002, by state

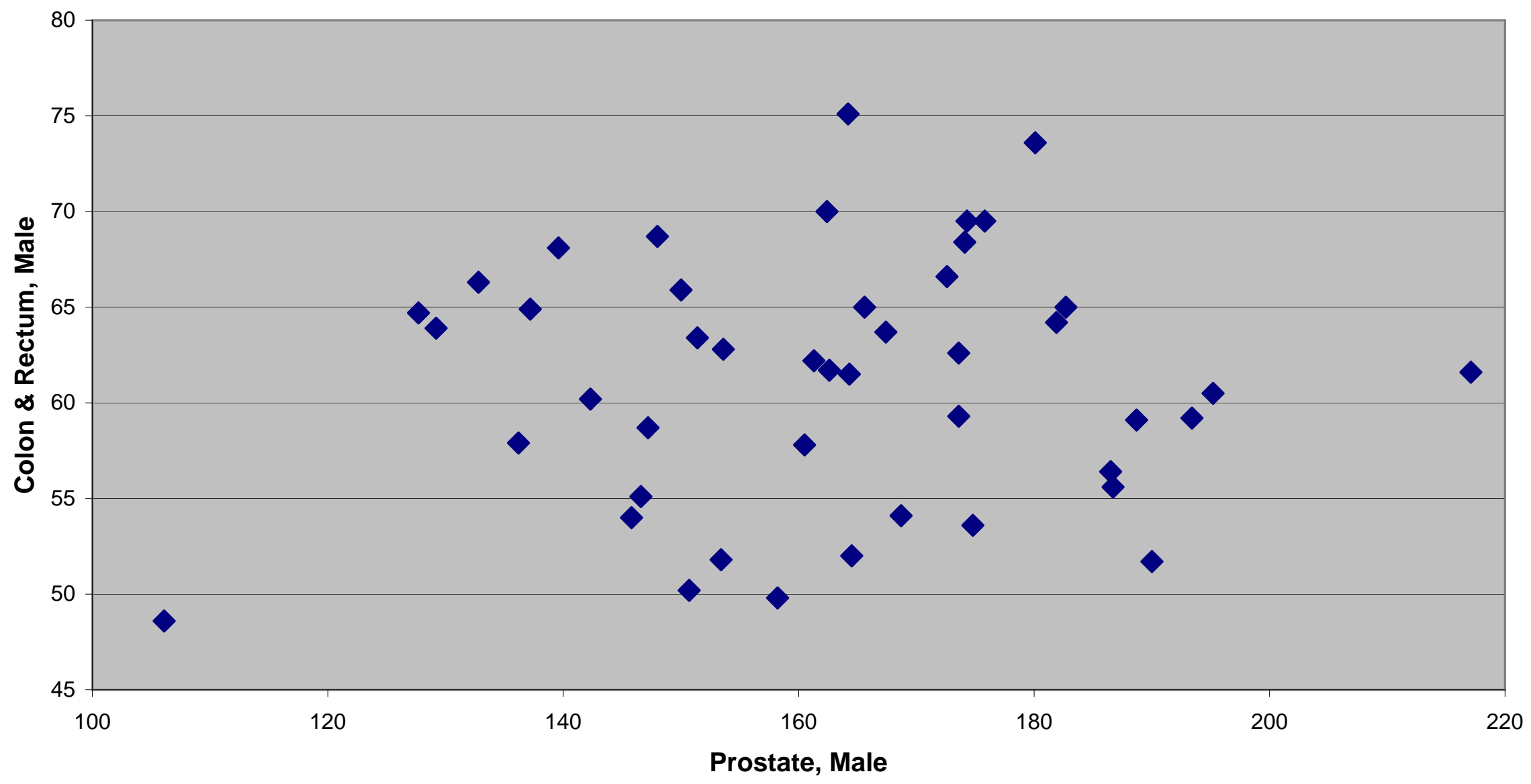

http://statecancerprofiles.cancer.gov/incidencerates/incidencerates.html 
Figure 8

Age-income and age-education profiles
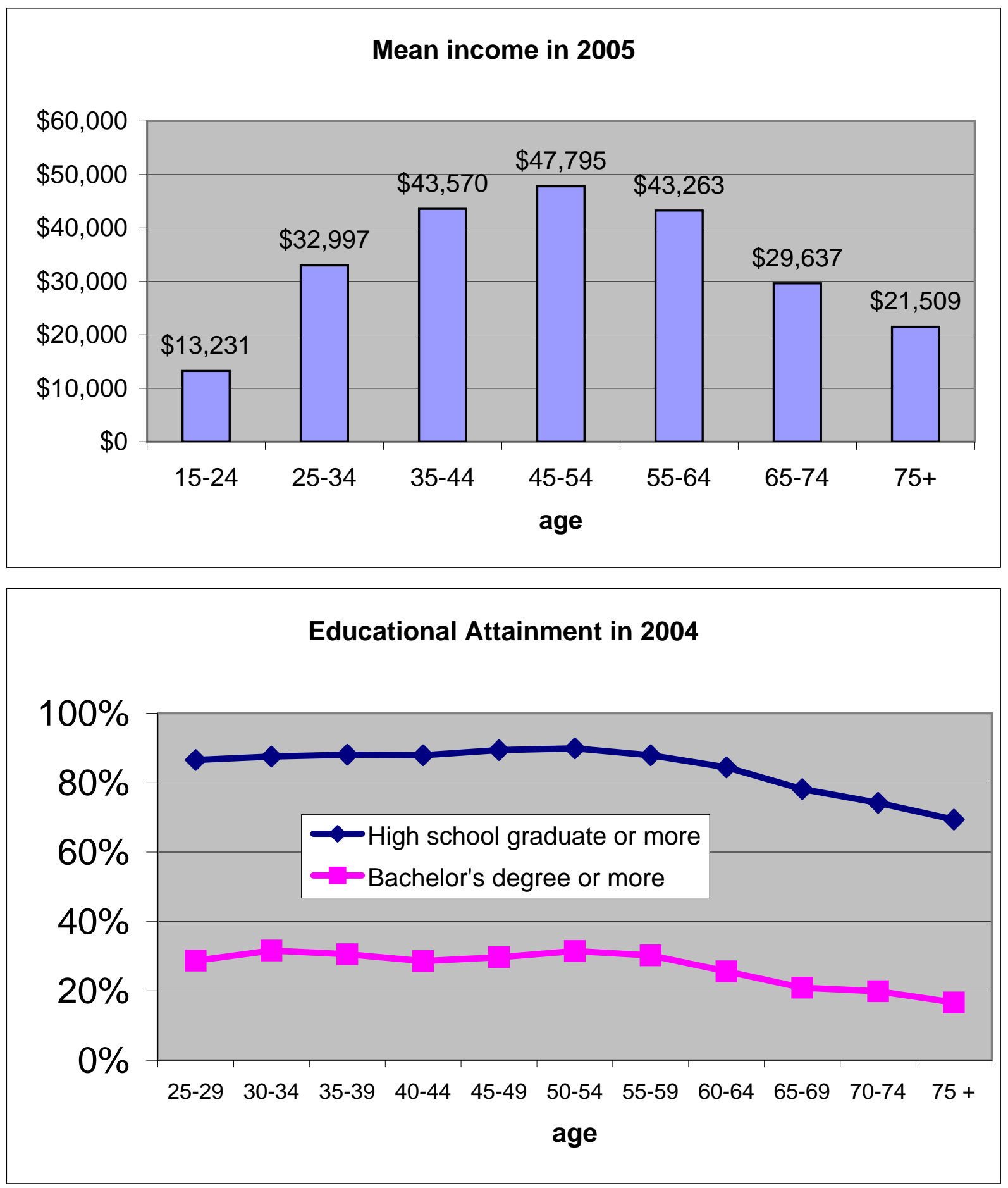
Figure 9

Comparison of population-weighted mean of

my state-level estimates of life expectancy at birth to NCHS national estimate

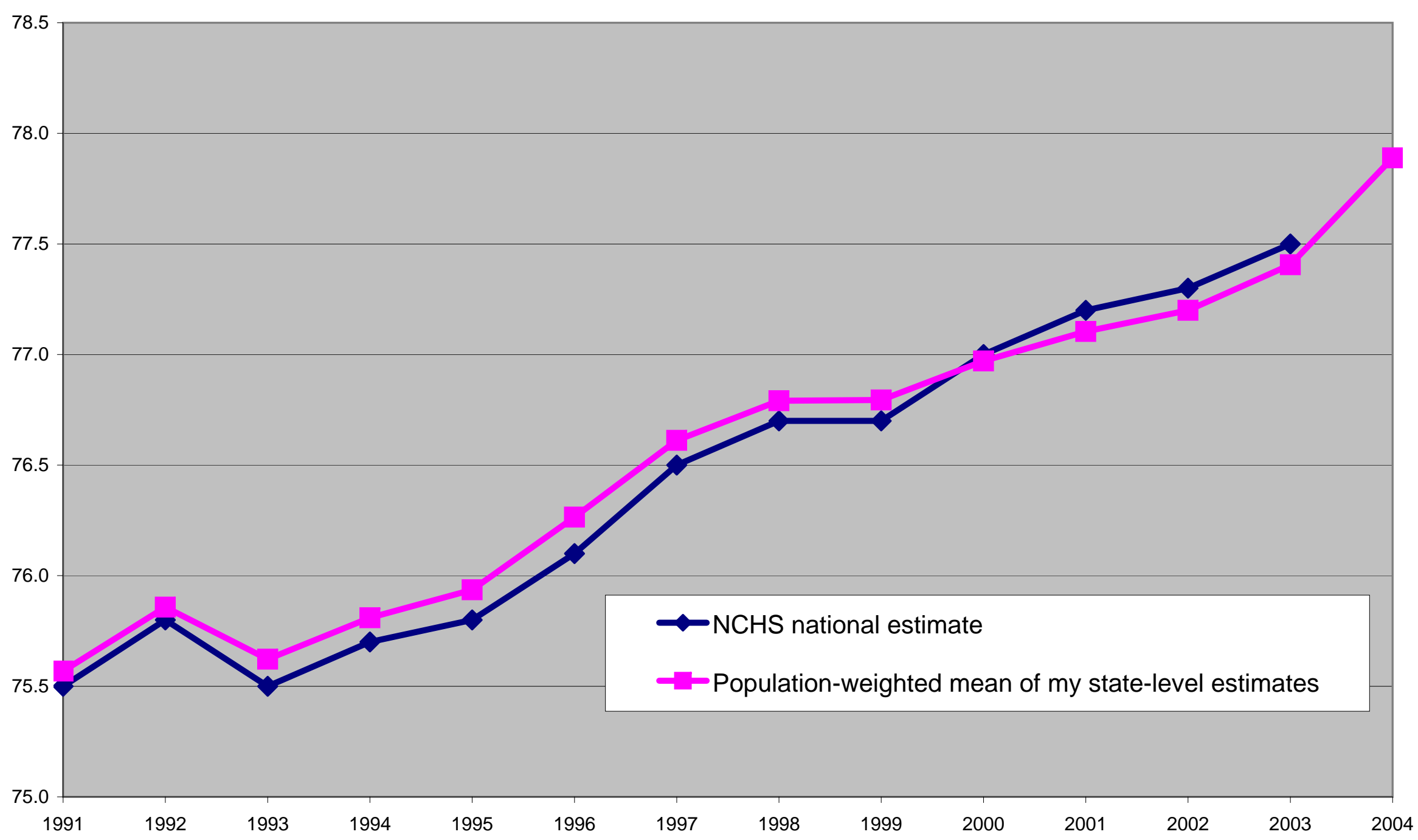


Figure 10

Increase in fixed-weighted drug vintage index 1991-2004, by state

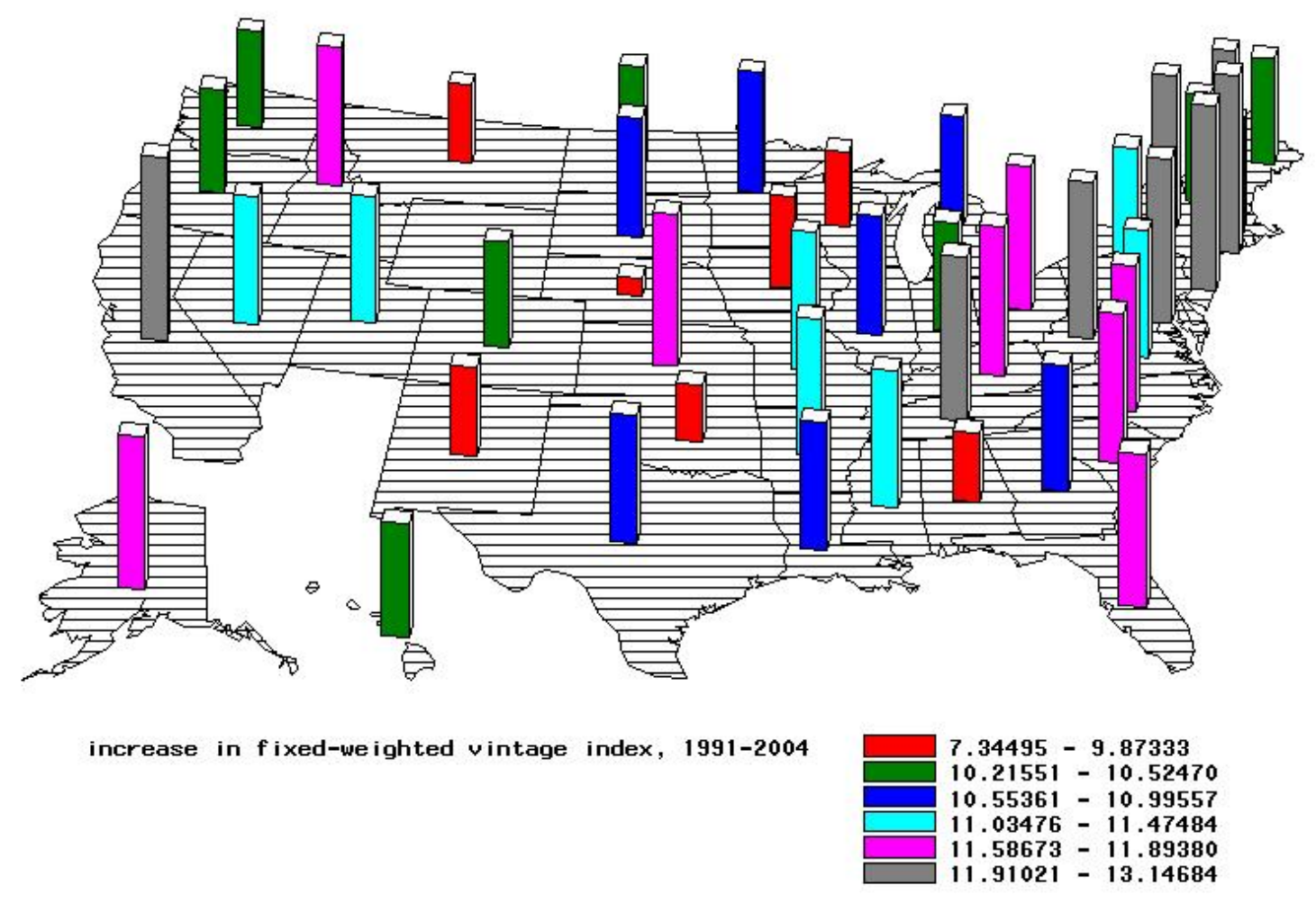


Figure 11

Diagnostic Imaging Services per 100,000 population, by age group, 2008

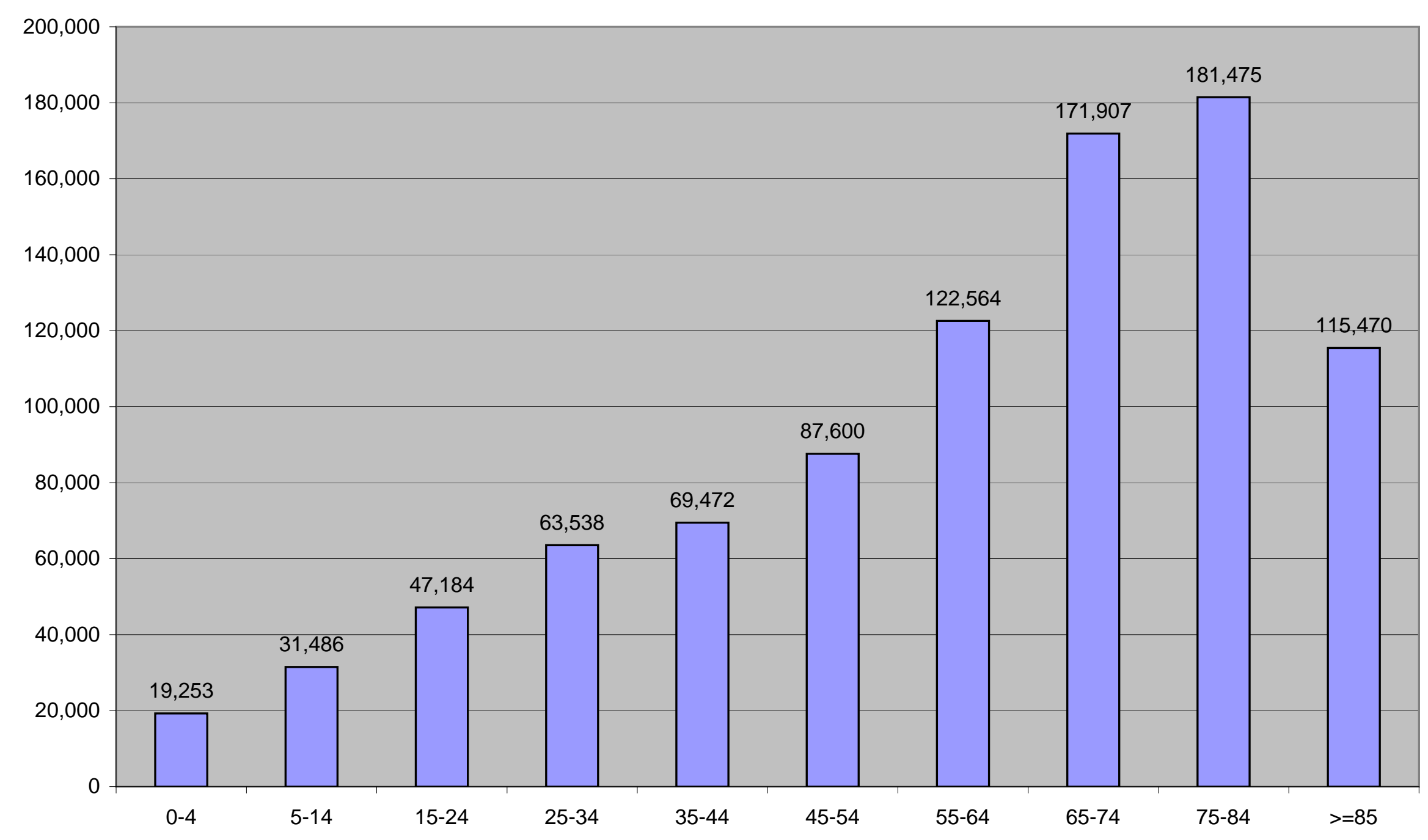




\section{Figure 12}

The relationship across demographic groups between the 1995-2004 increase in the number of advanced imaging procedures per capita and the 1995-2004 reduction in the log of the mortality rate
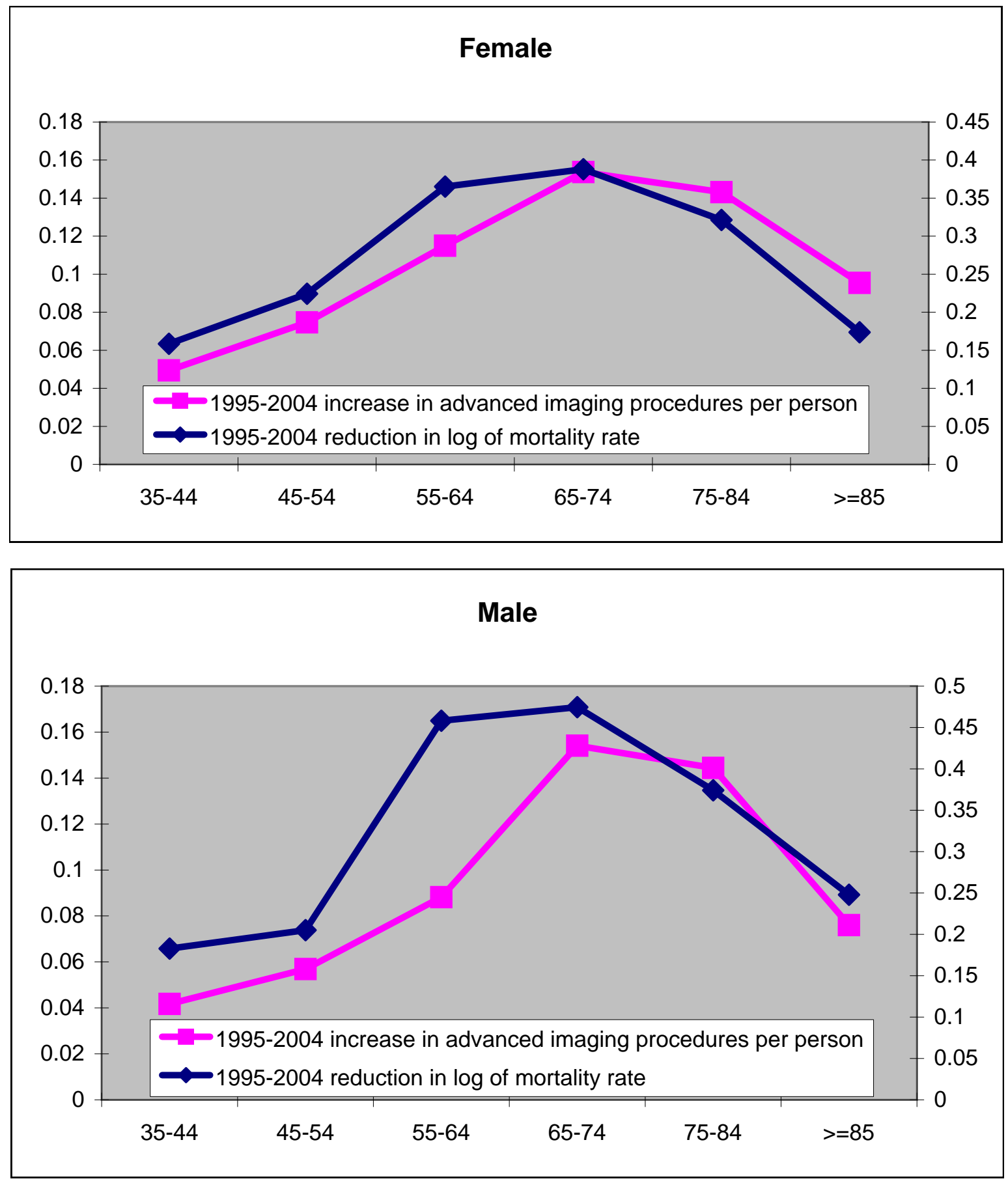


\section{Appendix A}

\section{Medicine Methodology - US News and World Report}

The 125 medical schools fully accredited by the Liaison Committee on Medical Education plus the 20 schools of osteopathic medicine fully accredited by the American Osteopathic Association were surveyed in the fall 2007 and early 2008. In order to determine the ranking of research medical schools; 126 schools responded to the survey. Of these schools, 126 provided the data needed to calculate the research rankings based on the indicators used in the research model. The same medical and osteopathic schools were surveyed for the primary-care ranking; 126 schools provided the data needed to calculate the primary-care ranking. The medical school research model is based on a weighted average of eight indicators, and the primary-care model is based on seven indicators. Both rankings are based on a weighted average of indicators, four of the data indicators are used in both the research and primary-care ranking model. The research model factors in research activity; the primary-care model adds a measure of the proportion of graduates entering primary-care specialties.

Quality Assessment (weighted by .40) Peer Assessment Score (.20 for the research medical school model, .25 for the primary-care medical school model) In the fall of 2007, medical and osteopathic school deans, deans of academic affairs, and heads of internal medicine or the directors of admissions were asked to rate programs on a scale from "marginal" (1) to "outstanding" (5). Survey populations were asked to rate program quality for both research and primary-care programs

separately on a single survey instrument. Those individuals who did not know enough about a school to evaluate it fairly were asked to mark "don't know." A school's score is the average of all the respondents who rated it. Responses of "don't know" counted neither for nor against a school. About 48 percent of those surveyed responded.

Assessment Score by Residency Directors (.20 for the research medical school model, .15 for the primary-care medical school model) In the fall of 2007, residency program directors were asked to rate programs on two separate survey instruments. One survey dealt with research and was sent to a sample of residency program directors in fields outside primary care, including surgery, psychiatry, and radiology. The other survey involved primary care and was sent to residency directors in the fields of family practice, pediatrics, and internal medicine. Survey recipients were asked to rate programs on a scale from "marginal" (1) to "outstanding" (5). Those individuals who did not know enough about a program to evaluate it fairly were asked to mark "don't know." A school's score is the average of all the respondents who rated it. Responses of "don't know" counted neither for nor against a school. About 25 percent of those surveyed for research medical schools responded; eighteen percent responded for primary-care. The source for the names for both of the residency directors surveys was the Graduate Medical Education Directory 2006-2007 edition, published by the American Medical Association. The peer scores from the America's Best Graduate Schools 2008 edition's residency directors' survey in non-primary care fields were used again for all schools in the research 
medical school model because of a printing error on the survey instrument mailed out in fall 2007. Assessment data collected by Synovate.

Research Activity (weighted by $\mathbf{. 3 0}$ in the research medical school model only) Total Research Activity (.20) Measured by the total dollar amount of National Institutes of Health research grants awarded to the medical school and its affiliated hospitals, averaged for 2006 and 2007. An asterisk indicates schools that reported only research grants to their medical school in 2007.

Average Research Activity Per Faculty Member (.10) Measured by the dollar amount of National Institutes of Health research grants awarded to the medical school and its affiliated hospitals per full-time faculty member, averaged over 2006 and 2007. Both fulltime basic sciences and clinical faculty were used in the faculty count. An asterisk indicates schools that reported research grants only to their medical school in 2007. Primary-Care Rate (.30 in the primary-care medical school model only) The percentage of M.D. or D.O. school graduates entering primary-care residencies in the fields of family practice, pediatrics, and internal medicine was averaged over 2005, 2006, and 2007.

Student Selectivity (.20 in the research medical school model, .15 in the primarycare medical school model)

Mean MCAT Score (.13 in the research medical school model, .0975 in the primarycare medical school model) The mean composite Medical College Admission Test score of the 2007 entering class.

Mean Undergraduate GPA (.06 in the research medical school model, .045 in the primary-care medical school model) The mean undergraduate grade-point average of the 2007 entering class.

Acceptance Rate (.01 in the research medical school model, .0075 in the primarycare medical school model) The proportion of applicants to the 2007 entering class who were offered admission.

Faculty Resources (.10 in the research medical school model, .15 in the primary-care medical school model) Faculty Resources were measured as the ratio of full-time science and full-time clinical faculty to full-time M.D. or D.O. students in 2007.

Overall Rank: Indicators were standardized about their means, and standardized scores were weighted, totaled, and rescaled so that the top school received 100; other schools received their percentage of the top score.

Specialty Rankings: The rankings are based solely on ratings by medical school deans and senior faculty from the list of schools surveyed. They each identified up to 10 schools offering the best programs in each specialty area. Those receiving the most nominations appear here. 


\section{Appendix B}

\section{Correlation across states between changes in the vintage of Medicaid and non- Medicaid prescriptions}

This appendix describes a test of the hypothesis that the extent of utilization of new drugs in the Medicaid program is strongly correlated with the extent of utilization of new drugs in general. We had access to data from a private company, NDCHealth, on the number of prescriptions, by NDC code, state (and five U.S. territories), month (January 2001-December 2003), and payer (Medicaid, other third party, and cash), for six important therapeutic classes of drugs: antidepressants, antihypertensives, cholesterollowering drugs, diabetic drugs, osteoporosis/menopause drugs, and pain management medications. Here are some summary statistics:

\begin{tabular}{|l|r|c|r|r|r|}
\hline & $\mathrm{N}$ & mean & std dev. & $\min$ & \multicolumn{1}{c|}{$\max$} \\
\hline & $252,469,702$ & 1986.44 & 1.51474 & 1961.22 & 2002 \\
\hline Medicaid & $2,244,589,497$ & 1986.59 & 1.19334 & 1980.47 & 1999 \\
\hline Other & \multicolumn{7}{|c|}{ FDA approval year } \\
\hline Total & $2,497,059,199$ & 1986.58 & 1.18352 & 1980.85 & 1999 \\
\hline & \multicolumn{7}{|c|}{ share of Rx's for drugs approved after 1980 } \\
\hline & $252,469,702$ & 0.81739 & 0.04221 & 0 & 1 \\
\hline Medicaid & $2,244,589,497$ & 0.80292 & 0.02936 & 0.5 & 1 \\
\hline Other & $2,497,059,199$ & 0.80438 & 0.0297 & 0.5 & 1 \\
\hline Total & 2,493 & & \\
\hline
\end{tabular}

These data were used to estimate the following equation: ${ }^{29}$

where

$$
\mathrm{Y}_{\mathrm{it}}=\pi \text { VINT_MEDICAID } \mathrm{it}_{\mathrm{i}}+\alpha_{\mathrm{i}}+\delta_{\mathrm{t}}+\varepsilon_{\mathrm{it}}
$$

\begin{tabular}{|r|l|}
\hline VINT_MEDICAID & $\begin{array}{l}\text { = the mean vintage (FDA approval year) of Medicaid rx's in state i } \\
\text { in month } \mathrm{t}\end{array}$ \\
\hline $\mathrm{Y}_{\text {it }}$ & $\begin{array}{l}\text { = the mean vintage of all rx's or of non-Medicaid (third-party and } \\
\text { cash) rx's in state } \mathrm{i} \text { in month } \mathrm{t}\end{array}$ \\
\hline$\alpha_{\mathrm{i}}$ & $=\mathrm{a}$ fixed effect for state $\mathrm{i}$ \\
\hline$\delta_{\mathrm{t}}$ & $=$ a fixed effect for year $\mathrm{t}$ \\
\hline$\varepsilon_{\mathrm{it}}$ & $=$ a disturbance \\
\hline
\end{tabular}

\footnotetext{
${ }^{29}$ This equation was estimated by weighted least-squares, weighting by the total number of rx's, or the number of non-Medicaid rx's, in state $i$ in month $t$.
} 
Two alternative measures of vintage were used: the mean FDA approval year, and the share of prescriptions containing active ingredients approved after 1980. Estimates of eq. (1) are shown in Table 1. In all four equations, the estimate of $\pi$ is positive and highly statistically significant ( $\mathrm{p}$-value $<.0001$ ). This indicates that the extent of utilization of new drugs in the Medicaid program is strongly correlated with the extent of utilization of new drugs in general. The vintage of non-Medicaid (and all) rx's tended to increase more in states with larger increases in the vintage of Medicaid rx's. 


\section{Appendix Table 1}

The relationship between the vintage of Medicaid rx's and the vintage of other (or all) rx's

\begin{tabular}{|c|c|c|c|c|}
\hline Model & $1 \mathrm{a}$ & $1 \mathrm{~b}$ & $2 \mathrm{a}$ & $2 \mathrm{~b}$ \\
\hline \begin{tabular}{|l} 
Dependent \\
Variable
\end{tabular} & $\begin{array}{c}\text { mean FDA approval } \\
\text { year of all rx's }\end{array}$ & $\begin{array}{c}\text { share of all rx's } \\
\text { containing active } \\
\text { ingredients approved } \\
\text { after } 1980 \\
\end{array}$ & $\begin{array}{c}\text { mean FDA approval } \\
\text { year of third-party \& } \\
\text { cash rx's }\end{array}$ & $\begin{array}{c}\text { share of third-party \& } \\
\text { cash rx's containing } \\
\text { active ingredients } \\
\text { approved after } 1980\end{array}$ \\
\hline Regressor & $\begin{array}{c}\text { mean FDA approval } \\
\text { year of Medicaid } \\
\text { rx's }\end{array}$ & $\begin{array}{c}\text { share of rx's } \\
\text { containing active } \\
\text { ingredients approved } \\
\text { after } 1980 \\
\end{array}$ & $\begin{array}{l}\text { mean FDA approval } \\
\text { year of Medicaid rx's }\end{array}$ & $\begin{array}{c}\text { share of Medicaid } \\
\text { rx's containing active } \\
\text { ingredients approved } \\
\text { after } 1980 \\
\end{array}$ \\
\hline Weight & total number of rx's & total number of rx's & $\begin{array}{c}\text { number of third-party } \\
+ \text { cash rx's } \\
\end{array}$ & $\begin{array}{c}\text { number of third-party } \\
+ \text { cash rx's }\end{array}$ \\
\hline$\pi$ & 0.291 & 0.316 & 0.237 & 0.253 \\
\hline std. err. & 0.012 & 0.013 & 0.013 & 0.014 \\
\hline t-stat & 25.19 & 23.98 & 18.98 & 17.75 \\
\hline $\mathrm{p}$-value & $<.0001$ & $<.0001$ & $<.0001$ & $<.0001$ \\
\hline
\end{tabular}

